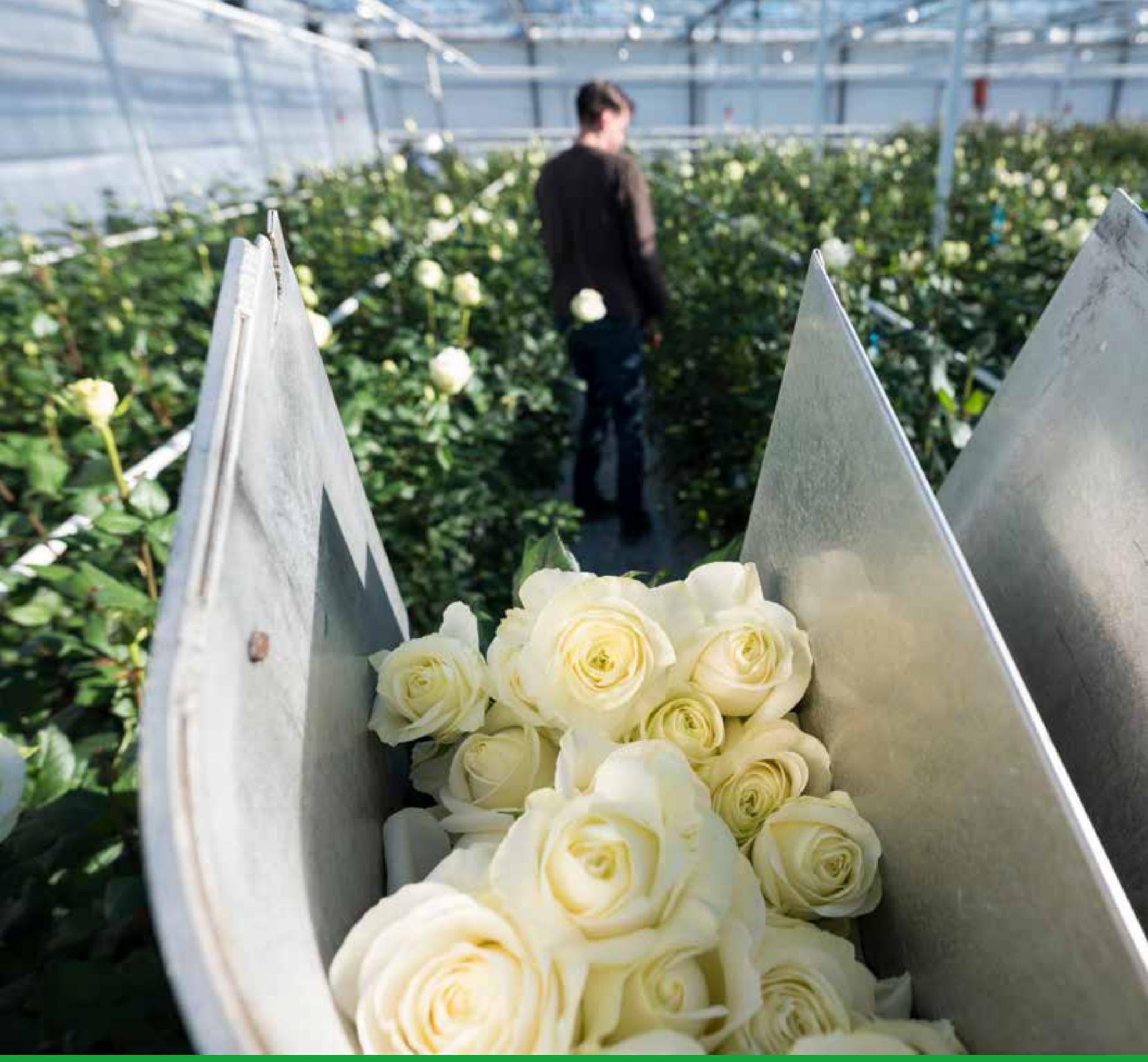

\title{
Environmental footprint of roses: representative product study
}

Roel Helmes, Pietro Goglio, Rick van der Linden, Irina Verweij-Novikova

WAGENINGEN

UNIVERSITY \& RESEARCH 



\section{Environmental footprint of roses: representative product study}

Roel Helmes, ${ }^{1}$ Pietro Goglio, ${ }^{1}$ Rick van der Linden, ${ }^{2}$ Irina Verweij-Novikova ${ }^{1}$

1 Wageningen Economic Research

2 Stichting Benefits of Nature

This study was carried out in the framework of the Public-Private Partnership project HortiFootPrint: 'Methodology for environmental footprint TU17005' for the Top sector Agri \& Food, as part of the Programme 'Consumer, Market and Society' (project number BO-61-001-007, BO-49-002-012).

Wageningen Economic Research

Wageningen, March 2021

This report was made possible by the Consortium Partners: Wageningen Economic Research, Blonk Consultants, PRé Sustainability, Foundation Benefits of Nature, MPS, Royal FloraHolland, Fresh Produce Centre, Glastuinbouw Nederland, ABN AMRO Bank N.V., Rabobank, Dutch Ministry of Agriculture, Nature and Food Quality.

REPORT

2021-018

ISBN 978-94-6395-731-1
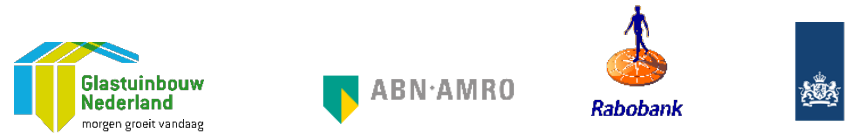
Roel Helmes, Pietro Goglio, Rick van der Linden, Irina Verweij-Novikova, 2021. Environmental footprint of roses: representative product study. Wageningen, Wageningen Economic Research, Report 2021-018. 36 pp.; 7 fig.; 16 tab.; 24 ref.

This it is not a stand-alone document but should be read in parallel to the report Hortifootprint category rules - towards a PEFCR for horticultural products (Helmes, R., T. Ponsioen, H. Blonk, M. Vieira, P. Goglio, R. van der Linden, P. Gual Rojas, D. Kan and I. Verweij-Novikova (2020). Wageningen, report 2020-041, Wageningen Economic Research. The summary of this report has been published in Environmental footprint of roses: Summary of the representative product study Helmes, R., P. Goglio and R. van der Linden (2020), Wageningen. Report 2020-041c.

This document represents a representative product study carried out in the context of the development of a methodology for calculating the environmental footprints of horticultural products, according to the newly released methodological standard - HortiFootprint category rules. The purpose of this product study was to identify the most relevant impact categories, life cycle stages, processes and direct elementary flows and also to identify the data needs, all feeding into the methodology development. This publication is meant as an illustration of a product environmental footprint (PEF) study for roses that are produced in a Dutch greenhouse with combined heat and power (CHP) system, transported across the main countries of export. The functional unit is one stem of $70 \mathrm{~cm}-$ long roses at commercial grade

Key words: life cycle assessment, Dutch rose, horticulture, environmental impact, glasshouse

This report can be downloaded for free at https://doi.org/10.18174/542609 or at www.wur.eu/economic-research (under Wageningen Economic Research publications).

(C) 2021 Wageningen Economic Research

P.O. Box 29703, 2502 LS The Hague, The Netherlands, T +31 (0)70 3358330 ,

E communications.ssg@wur.nl, http://www.wur.eu/economic-research. Wageningen Economic Research is part of Wageningen University \& Research.

\section{(cc) BY-NC}

This work is licensed under a Creative Commons Attribution-Non Commercial 4.0 International License.

(C) Wageningen Economic Research, part of Stichting Wageningen Research, 2021

The user may reproduce, distribute and share this work and make derivative works from it. Material by third parties which is used in the work and which are subject to intellectual property rights may not be used without prior permission from the relevant third party. The user must attribute the work by stating the name indicated by the author or licensor but may not do this in such a way as to create the impression that the author/licensor endorses the use of the work or the work of the user. The user may not use the work for commercial purposes.

Wageningen Economic Research accepts no liability for any damage resulting from the use of the results of this study or the application of the advice contained in it.

Wageningen Economic Research is ISO 9001:2015 certified.

Wageningen Economic Research Report 2021-018 | Project code 2282100273

Cover photo: Shutterstock 


\section{Contents}

$\begin{array}{ll}\text { Summary } & 5\end{array}$

$\begin{array}{ll}\text { Acronyms } & 7\end{array}$

1

$\begin{array}{lc}\text { Introduction } & \mathbf{8}\end{array}$

3.1 Function, functional unit and reference flow 10

3.2 System boundaries and system boundary diagram 10

3.3 Assumptions and value judgments 11

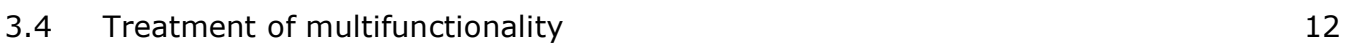

3.5 Information about the data used and data gaps 12

3.6 Impact categories, models and indicators 12

$\begin{array}{lll}3.7 & \text { Normalisation and weighting factors } & 13\end{array}$

4.1 Description and documentation of all unit process data 14

4.1.1 General approach 14

4.1.2 Case Specific Processes $\quad 15$

4.1.3 Generic Processes for PEFCR Horticulture 19

$\begin{array}{ll}4.2 & \text { Data collection procedures } \\ 4.3 & 20\end{array}$

4.3 Methodological assumptions used in the representative product study 20

4.3.1 Linking usage data to background (EcoInvent processes) datasets 20

4.3.2 Direct emissions of $\mathrm{C}, \mathrm{N}$ and $\mathrm{P}$ from fertilisers $\quad 21$

4.3.3 Including Plant Protection Products in LCA 21

5.1 Most relevant life cycle impact categories $\quad 22$

$\begin{array}{lll}5.2 & \text { Most relevant life cycle stages } & 23\end{array}$

$\begin{array}{lll}5.3 & \text { Impact indicator results of roses } & 24\end{array}$

5.4 Most relevant processes and elementary flows of roses $\quad 24$

5.4.1 Climate change $\quad 24$

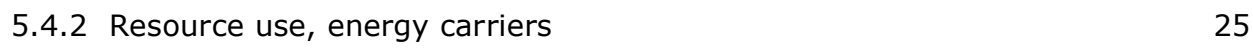

5.4.3 Acidification terrestrial and freshwater 26

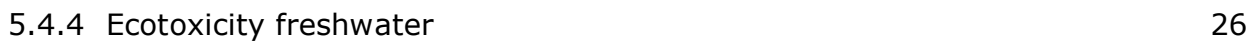

6.1 Climate change and resource use, energy 28

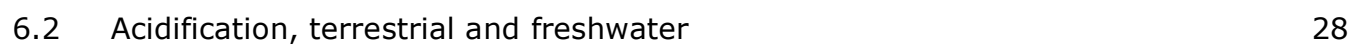

$\begin{array}{lll}6.3 & \text { Ecotoxicity, freshwater } & 28\end{array}$

$\begin{array}{lll}6.4 & \text { Other environmental impacts } & 28\end{array}$

7.1 Most relevant impact categories and life cycle stages $\quad 29$

$\begin{array}{lll}7.2 & \text { Most relevant processes } & 29\end{array}$

7.3 Overall appreciation of the uncertainties of the results 29

$\begin{array}{lll}7.4 & \text { Sensitivity analysis } & 30\end{array}$

$\begin{array}{lll}7.5 & \text { Data quality requirements } & 30\end{array}$ 
Figure 3.1 Figure 5.1

Figure 5.2

Figure 5.3

Figure 5.4

Figure $\mathbf{5 . 5}$

Figure $\mathbf{5 . 6}$

Table 3.1

Table 4.1

Table 4.2

Table 4.3

Table 4.4

Table 4.5

Table 4.6

Table 4.7

Table 4.8

Table 4.9

Table 4.10

Table 4.11

Table 4.12

Table 5.1

Table 5.2

Table 5.3
Product system processes and elementary flows

Contribution of the life cycle impact categories to the normalised and weighted impact of roses

Contribution of the life cycle stages of rose stem to the relevant impact categories

Contribution of the most relevant processes to at least $80 \%$ of the climate change impact of 1 stem $70 \mathrm{~cm}$ rose

Resource use, energy carriers impact in MJ per 1 stem of $70 \mathrm{~cm}$ of roses per life cycle stage and relevant process

Acidification terrestrial and freshwater impact in mol $\mathrm{H}+$ eq per $\mathrm{FU}$ (per 1 stem $70 \mathrm{~cm}$ rose) per life cycle stage and relevant process Freshwater ecotoxicity impact in CTUe per FU $\mathrm{FU}^{-1}$ ( 1 stem $70 \mathrm{~cm}$ rose) per life cycle stage and relevant process

Key aspects of the functional unit

Inputs, outputs, elementary flows and land use of the cultivation process

Inputs, outputs, elementary flows of the rose plant protection

Inputs, outputs, elementary flows and land use of the rose packaging (secondary and tertiary)

Inputs, outputs, elementary flows and land use of the rose cart production and use

Inputs, outputs, elementary flows and land use of the single use of the 577 bucket, including production \& cleaning Inputs, outputs, elementary flows and land use for storage of a single rose stem

Inputs, outputs, elementary flows and land use for international transport of a single rose stem

Inputs, outputs, elementary flows and land use for retail of $170 \mathrm{~cm}$ rose stem

Inputs, outputs, elementary flows and land use for the use of $170 \mathrm{~cm}$ rose stem

Inputs, outputs, elementary flows and land use for the disposal of 1 stem $70 \mathrm{~cm}$ rose Inputs, outputs, elementary flows and land use of the CHP production Inputs, outputs, elementary flows and land use of the flue gas treatment purified carbon dioxide production (or from external source)

Contribution of the most relevant processes and life cycle stages to the most relevant impact categories of roses 


\section{Summary}

This representative product study (RP study) was done in the context of the development of a methodology for calculating the environmental footprints of horticultural products, the HortiFootprint Category Rules (HFCR, see Helmes et al. 2020 (a)).

In the HFCR, a RP study is a preliminary study carried out on the representative product(s) and intended to identify the most relevant life cycle stages, processes, elementary flows, impact categories and data quality needs to derive the preliminary indication about the definition of the benchmark for the product category/sub-categories in scope, and any other major requirement to be part of the final PEFCR.

While the latest PEFCR Guidelines 2019 (Zampori and Pant, 2019) stimulate developing the Category Rules for a virtual product category (calculated based on average European market sales-weighted characteristics of all existing technologies/materials covered by the product category or sub-category), the HFCR followed the previous version of the earlier Guidelines (2018) and engaged into six RP studies. The RP studies have been performed as prescribed in the previous version of the Guidelines, namely EC (2018) where these studies are referred to as 'screening studies'.

This RP study is one of the six studies on horticultural representative products that have been selected based on a wide and economically relevant variety of applied technologies and origins of productions. The other five studies are:

- Phalaenopsis (ornamental plant cultivated in two stages, in substrate and in greenhouse)

- Tulip bulbs (annual crop in soil, grown without greenhouse protection, with ornamental function)

- Tomatoes (annual vegetable cultivated in greenhouse, on substrate)

- Bananas (tropical perennial fruit with variability in energy-consuming global transport)

- Apples (temperate perennial fruit with variability in energy-consuming storage and global transport).

This is the full version of this RP study report. A short summary of this study can be found in Helmes et al. (2020b). The study was finalised in Spring 2019.

The objectives of this study were:

- To identify the most relevant impact categories, life cycle stages and processes

- To determine the data (quality) requirements

- To test the draft HFCR: in particular, to provide input to check it for completeness and clarity, and to check the feasibility of completing a study in accordance with this.

This report describes the screening study for roses, produced in a Dutch greenhouse with combined heat and power (CHP) system, transported across the main countries of export. The functional unit (FU) is one stem of $70 \mathrm{~cm}$-long roses at commercial grade. The system includes a greenhouse structure (built from glass, steel, aluminium, concrete, etc.) with a CHP unit with a flue gas cleaner to provide heat, electricity and purified carbon dioxide. The number of roses per unit area was derived from primary data.

The most relevant impact categories, which contribute cumulatively to at least $80 \%$ of the normalised and weighted life cycle results of this study, were:

- Climate change

- Resource use, energy carriers

- Terrestrial and freshwater acidification.

The most relevant life cycle stages of the studied rose are cultivation (which includes capital goods, energy production, carbon dioxide and other activities) and transport. 
The RP study is NOT intended to make statements about the product group impacts as such, nor is it intended to be used in the context of comparison or for comparative assertions to be disclosed to the public. The results can be used to see where potential hotspots are by looking at the most relevant impact categories, life cycle stages, processes and elementary flows.

In practice, there is a large variety in greenhouse production of roses in respect to how energy is produced, and what sources of energy and purified carbon dioxide, and in what quantities, they are used. In many cases, a mix of different sources are used and the quantities will vary year by year due to weather conditions and economic developments. So, the absolute results of the current cases cannot be regarded as representative of the large variety in practice, but it is expected that the general conclusions on the hotspots and the resulting data quality requirements will apply to heated and protected production in European temperate climate zones. 


\section{Acronyms}

\begin{tabular}{ll} 
Abbreviation & Explanation \\
CHP & Combined Heat and Power \\
\hline CPA & Classification of Products by Activity \\
\hline EF & Environmental Footprint \\
\hline EU & European Union \\
\hline FU & Functional Unit \\
\hline hHG & Greenhouse Gas \\
\hline ha & hectare \\
\hline kg & Hortifootprint Category Rules \\
\hline km & kilogram \\
\hline KWh & kilometre \\
\hline LCA & kilowatt-hour \\
\hline LCI & Life Cycle Assessment \\
\hline LCIA & Life Cycle Inventory \\
\hline$m$ & Life Cycle Impact Assessment \\
\hline$m^{2}$ & metre \\
\hline$m^{3}$ & square metre \\
\hline$M J$ & cubic metre \\
\hline PEF & megajoule \\
\hline PEFCR & Product Environmental Footprint \\
\hline & Product Environmental Footprint Category Rules \\
\hline in
\end{tabular}




\section{Introduction}

This representative product study (RP study) was done in the context of the development of a methodology for calculating the environmental footprints of horticultural products, the HortiFootprint Category Rules (HFCR). The development of the methodology followed as much as possible the most recent Guidance for developing Product Environmental Category Rules (PEFCR) published by the European Commission. The HortiFootprint Category Rules (HFCRs) is a set of life-cycle-based rules for the 16 environmental impact categories. Among these categories are climate change, land use and resource depletion. Within horticulture, this methodology applies to fruits and vegetables as well as flowers and plants.

This report is not a stand-alone document but should be read in parallel to the HFCR report. In the HFCR context, a representative product study (RP study) is a preliminary study carried out on the representative product(s) and intended to identify the most relevant life cycle stages, processes, elementary flows, impact categories and data quality needs to derive the preliminary indication about the definition of the benchmark for the product category/sub-categories in scope, and any other major requirement to be part of the final PEFCR.

While the latest PEFCR Guidelines 2019 (Zampori and Pant, 2019) stimulate developing the Category Rules for a virtual product category (calculated based on average European market sales-weighted characteristics of all existing technologies/materials covered by the product category or sub-category), the HFCR followed the previous version of the earlier Guidelines (2018) and engaged in six RP studies. The RP studies (representative product studies) have been performed as prescribed in the previous version of the Guidelines, namely EC (2018) where these studies are referred to as 'screening studies'.

This RP study is one of the six studies on horticultural representative products that have been selected based on a wide and economically relevant variety of applied technologies and origins of productions. The other five studies were:

- Phalaenopsis (ornamental plant cultivated in two stages, in substrate and in greenhouse). For a published summary, see Helmes et al. (2020c)

- Tulip bulbs (annual crop in soil, grown without greenhouse protection, with ornamental function). For a published summary, see Goglio (2020)

- Tomatoes (annual vegetable cultivated in greenhouse, on substrate). For a published summary, see Ponsioen and Helmes (2020a)

- Bananas (tropical perennial fruit with variability in energy-consuming global transport). For a published summary, see Kan et al. (2020)

- Apples (temperate perennial fruit with variability in energy-consuming storage and global transport). For a published summary, see Ponsioen and Helmes (2020b).

This is the full version of this RP study report. Short summary of this study can be found in Helmes et al. (2020b). The study was finalised in Spring 2019.

The development of the HFCR was initiated by Royal FloraHolland, Dutch Fresh Produce Center and Wageningen Economic Research, with co-financing from the Dutch Fund for Horticulture \& Propagation Materials, ABN AMRO Bank N.V., the Dutch sector organisation for greenhouse horticulture (Glastuinbouw Nederland), MPS, Rabobank, Foundation Benefits of Nature and in co-production with experts from Blonk Consultants and PRé Sustainability. 


\section{Goal of the study}

The objectives of this study are:

- To identify the most relevant impact categories, life cycle stages and processes

- To determine the data (quality) requirements

- To test the draft HFCR: in particular, to provide input to check it for completeness and clarity, and to check the feasibility of completing a study in accordance with this.

This report describes the RP study for roses, produced in a Dutch greenhouse with a combined heat and power (CHP) system, transported across the main countries of export. The functional unit (FU) is one stem of $70 \mathrm{~cm}$-long roses at commercial grade.

The system includes a greenhouse structure (built from glass, steel, aluminium, concrete, etc.) with a CHP unit with a flue gas cleaner to provide heat, electricity and purified carbon dioxide. The number of roses per unit area was derived from primary data.

The rose bushes are grown by planting propagation material in soil and the crop is then managed with fertilisers, water and pesticides. Surplus electricity produced in the CHP is supplied to the grid. After harvest the roses are refrigerated for one day and distributed to retail shops. The use of roses was also accounted together with their disposal.

Main limitations:

- The RP study is NOT intended to make statements about the product group impacts as such, nor is it intended to be used in the context of comparison or for comparative assertions to be disclosed to the public.

- In practice there is a large variety in greenhouse production of roses in respect to how energy is produced, and what sources of energy and purified carbon dioxide and in what quantities they are used. In many cases, a mix of different sources are used and the quantities will vary year by year due to weather conditions and economic developments. So, the absolute results of the current cases cannot be regarded as representative of the large variety in practice, but it is expected that the general conclusions on the hotspots and the resulting data quality requirements will apply to heated and protected production in European temperate climate zones. 


\section{Scope of the study}

\subsection{Function, functional unit and reference flow}

When developing Category Rules (CR) for horticultural products falling under one product category horticulture - it is recognised that rules should be fine-tuned to the specifics of the horticultural products, in particularly to Functional Unit (FU), reference flows and issues around data collection in this guideline.

The functional unit of product is described in Table 3.1. The functional unit defines the qualitative and quantitative aspects of the function(s) and/or service(s) provided by the product being evaluated. The functional unit definition answers the questions 'what?', 'how much?', 'how well?', and 'for how long?'

Table 3.1 Key aspects of the functional unit

\begin{tabular}{|c|c|}
\hline Aspect & Defined in this RP study \\
\hline What (function provided)? & $\begin{array}{l}\text { Rose ( } 1 \text { stem of } 70 \mathrm{~cm} \text { ) packaged in a bunch of } 10 \text { stems in polypropylene film, produced } \\
\text { in a greenhouse with CHP, distributed as an average flower from the Netherlands and } \\
\text { consumed at the country of export. }\end{array}$ \\
\hline How much (reference flow)? & 1 Rose flower ( 1 stem) with packaging \\
\hline How well (quality)? & Standard quality of a rose within a producing company \\
\hline
\end{tabular}

\subsection{System boundaries and system boundary diagram}

The life cycle assessment has been carried out with a cradle-to-grave approach. Thus the system boundary includes: the transport of all the agricultural inputs (i.e. fertiliser, pesticide, cuttings) from the cradle to the disposal of the rose stem. The cultivation includes a glass, steel and aluminium greenhouse structure with a CHP unit with flue gas treatment to provide heat, electricity and purified carbon dioxide. The rose bushes are grown from rose cuttings and the crop is then managed with fertilisers, water and pesticides. Surplus electricity is supplied to the grid. After harvest the rose stems are packed and transported to retail, then consumed and the packaging and excess organic material is treated at disposal (Figure 3.1). The capital goods, carbon dioxide and energy production and cultivation sub-stages belong to the cultivation stage. The storage stage was assumed to last one day.

The following processes are excluded:

- Capital goods at distribution centre and at retail: due to the small contribution and the low level of control capital goods are often excluded from the background processes if they are not included in secondary data.

- Tools used to prune the roses: these are considered negligible.

- Energy production for storage at ambient conditions at the consumer: this is considered negligible.

- Soil C dynamics as it is outside the proposed PEFCR guidance. 


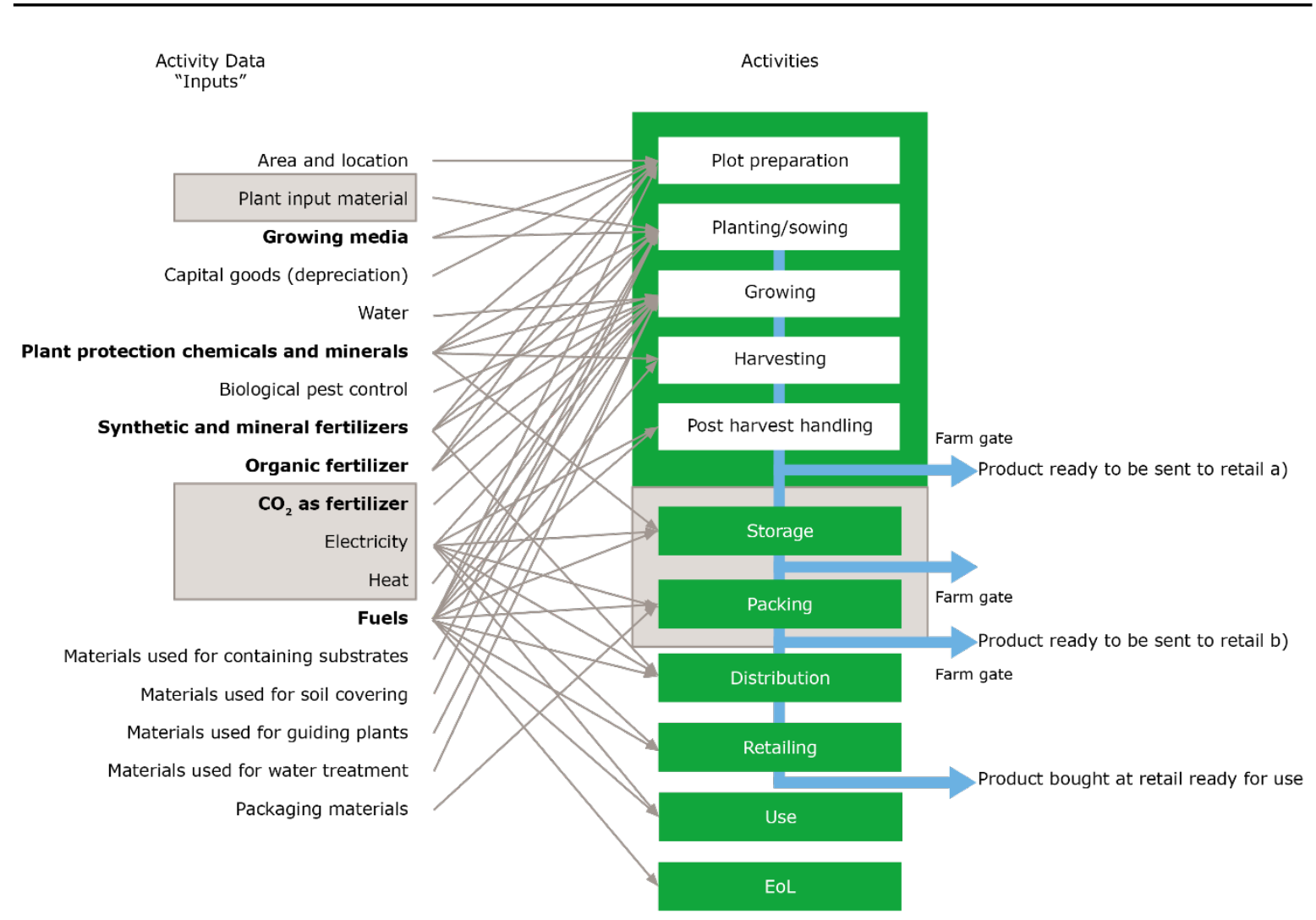

Figure 3.1 Product system processes and elementary flows

In Figure 3.1, the life cycle stages (dark green) shall be are presented in the results if they occur and when in scope. Cultivation at a farm always includes 5 subgroups of activities: plot preparation; planting or sowing; growing; harvesting and post-harvest handling. Storage and packing can take place at the farm, it may also be a separate operation outside the farm. Greenhouse farmers can also produce their own heat, electricity or $\mathrm{CO}_{2}$ fertiliser in a central heat and power (CHP) unit. A part of a horticulture farm can also be designated to the production of young plant material. Farm activities require inputs (activity data). Those are listed on the left-hand side. In the LCA activity data are connected to production processes which cause interventions (emissions and resource use) or they are used as input for emissions modelling.

\subsection{Assumptions and value judgments}

The following assumptions and value judgments were made, along with justifications for the assumptions.

The heat production efficiency was assumed at $48 \%$ and the electricity production efficiency $40 \%$. These efficiencies are not commonly measured by the growers.

The technical lifetime of the capital goods for cultivation (greenhouse structure) is assumed to be 15 years. In practice, growers may use the greenhouse structure for longer, which would mean that the impact of the material production and construction will be lower. The currently assumed high depreciation of capital goods is a conservative estimate. Longer lifetimes must be substantiated with evidence that the structure will be kept in operation longer than 15 years. Because this technology is relatively new in the horticultural sector, it is difficult to accurately estimate this number. It may need more substantiation.

Land use change: no land use change is associated with horticultural production in the Netherlands. No accounting is carried out for soil $\mathrm{C}$ in agreement with the PEFCR guidance. 
Each $\mathrm{m}^{2}$ of land produce 400 stems per year of acceptable commercial quality. The rose bush will last 10 years. After that the soil is tilled with a petrol rotavator with a power of $3.96 \mathrm{~kW}$. The residues are composted. It was assumed that transport of rose stems was refrigerated all the time. Electricity mixes: the national electricity mix is used as given by the background database. The transport of the roses is accounted for on the basis of the export market for flowers in Netherland, as it was assumed that roses will be grown in Dutch conditions. Distances were estimated on average for each export country using Google Maps. This was combined with EcoInvent data for each transport process. Transport processes were accounted for considering the return journey.

A short storage for roses ( 1 day) is assumed. Data for retail were obtained from the project expert group. During retail the water in each bucket is replaced and the same bucket used for transport was assumed. The plastic wrap is changed for delivery to the customer. During the use stage a cilindrical vase with a diameter of $10 \mathrm{~cm}$, a height of $15 \mathrm{~cm}$ and a thickness of $3 \mathrm{~mm}$ was used a 100 times. The vase is filled with $7.5 \mathrm{~cm}$ of water. Once used, the rose stem is sent to a composting facility.

\subsection{Treatment of multifunctionality}

These sections provide documentation and justification of the treatment of multifunctionality issues encountered in the PEF modelling activity. No distinction is made between quality classes of roses. Hence, there is only one foreground process where co-production takes place, which is the energy production (CHP).

For the CHP used to heat the greenhouse where rose bushes are grown, surplus electricity is sold by the grower to the grid. This multifunctionality was handled by first subdividing the system: the CHP unit, the flue gas treatment that produces purified carbon dioxide for stimulating crop growth and the cultivation processes are divided into separate unit processes. So, the only multifunctional process is then the production of heat and electricity, where the flue gas is not considered as a co-product, but as emissions, which are attributed to the CHP process. All emissions captured by the flue gas treatment are emitted during the rose life cycle and are not included in the emission inventory.

Energy allocation between electricity and heat is chosen because there is a clear relationship between the energy content of the natural gas input (upper heating value) and the energy of the electricity and the heat produced. The consequences of applying exergy allocation is explored in a sensitivity analysis. The rationale behind the chosen method is explained in detail in Ponsioen et al. (2020).

\subsection{Information about the data used and data gaps}

Information about the data used and data gaps refers to:

- Data representativeness, appropriateness of data, and types/sources of required data and information; includes information on data quality requirements and generic data sources including the data quality scores according to the EF requirements.

- Assessment of the precision, completeness and representativeness of data used.

This is described in Chapter 4.

\subsection{Impact categories, models and indicators}

The EF LCIA method was applied. No additional impact categories are used; although the impact category ecotoxicity freshwater is not considered as a possible relevant impact category in the selection procedure, it is selected as relevant because of the perceived relevance due to expected impact of pesticide use. 


\subsection{Normalisation and weighting factors}

Normalisation and weighting from the EF LCIA method were applied to select the most relevant impact categories. 


\section{$4 \quad$ Compiling and recording the life cycle inventory analysis}

\subsection{Description and documentation of all unit process data}

This section gives a qualitative and quantitative description and documentation of all unit processes, including for each life cycle stage. A unit process is the smallest element considered in the life cycle inventory for which input and output data are quantified (based on ISO 14040:2006). Tables with all processes involved are given, including inputs, outputs, elementary flows and land use. The processes described in Tables 4.1, 4.3, 4.5-4.10 reflect the life cycle stages. These are grouped in an overarching process. For each dataset used the source is specified together with an assessment of its data quality, based on the PEF data quality assessment approach. Next, the values needed for assessing the data quality rating (DQR) of the datasets are presented. The calculation of the DQR shall be based on four data quality criteria:

$D Q R=(T e R+G e R+T i R+P) / 4$

where TeR is the Technological-Representativeness, GeR is the Geographical-Representativeness, TiR is the Time-Representativeness, and $\mathrm{P}$ is Precision. The representativeness (technological, geographical and time-related) characterises to what degree the processes and products selected are depicting the system analysed, while the precision indicates the way the data is derived and related level of uncertainty.

\subsubsection{General approach}

Foreground data was collected as averaged primary data from rose-growing operations in the Netherlands as compiled by Benefits of Nature, and augmented with data from literature. For storage, retail and the use stages, datasets were created using default data for these, processed using the PEFCR guidance documentation (EC, 2018). The end of life was modelled using details from Annex C from the same document.

For the background data, EcoInvent version 3.4 cut-off was used (Wernet et al., 2016) as well as Agrifootprint 4.0 (economic, see Agri-footprint 2018 a,b). The EF Life Cycle Inventory (LCI) database could not be used, because the original study was not part of an official PEF pilot by the European Commission, as it was conducted before the current transition phase. The modelling was done in SimaPro version 8.5.2, following the PEF rules at that time (EC, 2018).

All calculations for LCI and LCIA were done in SimaPro 8.5.2.0. The default EF impact assessment method (version of October 2018) was used with European normalisation and equal weighting. The PEF impact assessment results are relative expressions and do not predict impacts on category endpoints, the exceeding of thresholds, safety margins or risks. 


\subsubsection{Case Specific Processes}

Table 4.1 Inputs, outputs, elementary flows and land use of the cultivation process

\begin{tabular}{|c|c|c|c|c|c|c|c|c|c|}
\hline Inputs, products, interventions & Amount & Unit & Reference & TeR & GeR & TiR & $\mathbf{P}$ & & DQR \\
\hline \multicolumn{10}{|l|}{ Products } \\
\hline Rose stems at commercial grade & 1 & stem & & & & & & & \\
\hline \multicolumn{10}{|l|}{ From Nature } \\
\hline Occupation, industrial area & 0.0025 & $\mathrm{~m} 2 \mathrm{a}$ & (1) & & 1 & 1 & 1 & 2 & 1.25 \\
\hline Water, rain & $9.08 \mathrm{E}-01$ & 1 & (1) & & 2 & 1 & 1 & 2 & 1.5 \\
\hline Carbon dioxide, in air & 42.2 & $\mathrm{~g}$ & (1) & & 2 & 1 & 1 & 2 & 1.5 \\
\hline Carbon dioxide, in air & $2.95 \mathrm{E}-03$ & g & (1) & & 2 & 1 & 1 & 2 & 1.5 \\
\hline \multicolumn{10}{|l|}{ Input from the technosphere } \\
\hline $\begin{array}{l}\text { Greenhouse, glass walls and roof }\{\mathrm{GLO}\} \mid \text { market } \\
\text { for greenhouse, glass walls and roof | Cut-off, } \mathrm{S}\end{array}$ & 0.0025 & $\mathrm{~m} 2 \mathrm{a}$ & (1) & & 1 & 1 & 1 & 2 & 1.25 \\
\hline $\begin{array}{l}\text { Heat and power cogeneration unit, } 1 \mathrm{MWel} \text {, } \\
6.4 \mathrm{MWth}\{\mathrm{GLO}\} \mid \text { market for heat and power }\end{array}$ & $4.72 \mathrm{E}-09$ & $\mathrm{p}$ & (1) & & 2 & 3 & 2 & 2 & 2.25 \\
\hline
\end{tabular}

\begin{tabular}{|c|c|c|c|c|c|c|c|}
\hline $\mathrm{CO}_{2}$ from OCAP & $1.69 \mathrm{E}-02 \mathrm{~kg}$ & (2) & 1 & 1 & 1 & 1 & 1 \\
\hline $\mathrm{CO}_{2}$ from tank & $3.10 \mathrm{E}-02 \mathrm{~kg}$ & (2) & 1 & 1 & 1 & 1 & \\
\hline Packaging, for fertilisers or pesticides $\{\mathrm{GLO}\} \mid$ & $1.53 \mathrm{E}-02 \mathrm{~kg}$ & (1) & 2 & 3 & 2 & 2 & 2.25 \\
\hline
\end{tabular}

packaging production for liquid fertiliser or

pesticide, per kilogram of packed product | Cut-

off, $\mathrm{S}$

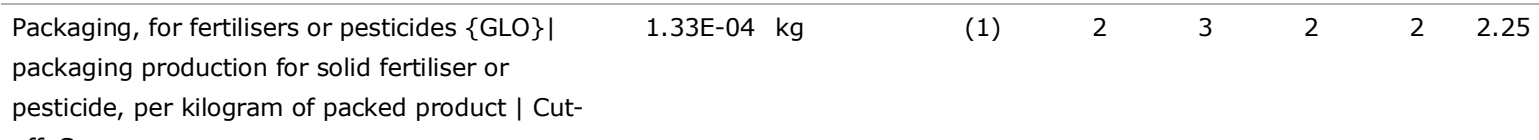

off, $\mathrm{S}$

\begin{tabular}{|c|c|c|c|c|c|c|c|c|}
\hline Elec WKK NL & 1.01 & kWh & $(1),(2)$ & 1 & 1 & 1 & 1 & 1 \\
\hline Heat WKK NL & 6.93 & MJ & $(1),(2)$ & 1 & 1 & 1 & 1 & 1 \\
\hline $\begin{array}{l}\text { Aluminium sulfate, powder }\{\mathrm{GLO}\} \mid \text { market for | } \\
\text { Cut-off, } \mathrm{S}\end{array}$ & 8.97E-06 & $\mathrm{kg}$ & (1) & 2 & 3 & 2 & 2 & 2.25 \\
\hline Magnesium sulfate $\{\mathrm{GLO}\} \mid$ market for | Cut-off, $\mathrm{S}$ & 0.000354 & $\mathrm{~kg}$ & (1) & 2 & 2 & 2 & 2 & 2 \\
\hline $\begin{array}{l}\text { Ammonium nitrate, as } \mathrm{N}\{\mathrm{GLO}\} \mid \text { market for | } \\
\text { Cut-off, } \mathrm{S}\end{array}$ & 0.000046 & $\mathrm{~kg}$ & (1) & 2 & 2 & 2 & 2 & 2 \\
\hline $\begin{array}{l}\text { Phosphoric acid, fertiliser grade, without water, in } \\
70 \% \text { solution state }\{\mathrm{GLO}\} \mid \text { market for | Cut-off, S }\end{array}$ & 0.000220 & $\mathrm{~kg}$ & (1) & 2 & 2 & 2 & 2 & 2 \\
\hline $\begin{array}{l}\text { Potassium hydroxide }\{\mathrm{GLO}\} \mid \text { market for | Cut-off, } \\
\text { S }\end{array}$ & 0.000528 & $\mathrm{~kg}$ & (1) & 2 & 2 & 2 & 2 & 2 \\
\hline Calcium nitrate $\{\mathrm{GLO}\} \mid$ market for | Cut-off, $\mathrm{S}$ & 0.000725 & $\mathrm{~kg}$ & (1) & 2 & 2 & 2 & 2 & 2 \\
\hline $\begin{array}{l}\text { Nitric acid, without water, in } 50 \% \text { solution state } \\
\{G L O\} \mid \text { market for | Cut-off, } \mathrm{S}\end{array}$ & 0.000420 & $\mathrm{~kg}$ & (1) & 2 & 2 & 2 & 2 & 2 \\
\hline $\begin{array}{l}\text { Transport, freight, lorry } 16-32 \text { metric ton, EURO5 } \\
\{\text { GLO\}| market for | Cut-off, S }\end{array}$ & 0.001392 & $\mathrm{tkm}$ & (1) & 1 & 1 & 1 & 2 & 1.25 \\
\hline $\begin{array}{l}\text { Extrusion, plastic film }\{\mathrm{GLO}\} \mid \text { market for | Cut- } \\
\text { off, } \mathrm{S}\end{array}$ & 0.000635 & $\mathrm{~kg}$ & $(1),(3)$ & 2 & 3 & 2 & 2 & 2.25 \\
\hline $\begin{array}{l}\text { Polypropylene, granulate }\{\mathrm{GLO}\} \mid \text { market for I } \\
\text { Cut-off, S }\end{array}$ & 0.000635 & $\mathrm{~kg}$ & $(1),(3)$ & 2 & 3 & 2 & 2 & 2.25 \\
\hline Tree seedling $\{$ GLO $\} \mid$ market for | Cut-off, $\mathrm{S}$ & 0.00189 & $\mathrm{p}$ & (1) & 5 & 2 & 2 & 2 & 2.75 \\
\hline Hoeing rotavator & 0.0005 & $\mathrm{p}$ & (4) & 1 & 1 & 1 & 2 & 1.25 \\
\hline $\begin{array}{l}\text { Transport, freight, lorry } 16-32 \text { metric ton, EURO5 } \\
\{\text { GLO\}| market for | Cut-off, S }\end{array}$ & 0.397 & $\mathrm{kgkm}$ & (1) & 1 & 1 & 1 & 2 & 1.25 \\
\hline Roses plant protection & 1 & $\mathrm{p}$ & $(1),(2)$ & 3 & 3 & 4 & 4 & 3.5 \\
\hline \multicolumn{9}{|l|}{ Emissions to air } \\
\hline Ammonia & 0.013 & $\mathrm{~g}$ & $(1),(5)$ & 1 & 1 & 1 & 2 & 1.25 \\
\hline Dinitrogen monoxide & 0.00637 & $g$ & $(1),(5)$ & 1 & 1 & 1 & 2 & 1.25 \\
\hline Nitrogen oxides & $2.36 \mathrm{E}-01$ & $g$ & $(1),(5)$ & 1 & 1 & 1 & 2 & 1.25 \\
\hline Carbon dioxide, fossil & 0.0442 & $\mathrm{~kg}$ & (1) & 1 & 1 & 1 & 2 & 1.25 \\
\hline Dinitrogen monoxide & $2.53 \mathrm{E}-11$ & $\mathrm{~kg}$ & $(5),(6)$ & 1 & 1 & 1 & 2 & 1.25 \\
\hline Dinitrogen monoxide & $2.56 \mathrm{E}-06$ & $\mathrm{~kg}$ & $(5),(6)$ & 1 & 1 & 1 & 2 & 1.25 \\
\hline Nitrogen oxides & $4.14 \mathrm{E}-11$ & $\mathrm{~kg}$ & $(5),(6)$ & 1 & 1 & 1 & 2 & 1.25 \\
\hline
\end{tabular}




\section{Emissions to water}

Water, NL $9.08 \mathrm{E}-01$

Nitrate

$1.1 \mathrm{~g}$

(1)

1

Phosphate

$0.22 \mathrm{~g}$

$(1),(5)$

\section{To the technosphere (waste flows)}

Biowaste $\{N L\} \mid$ treatment of biowaste (as DRY MASS), industrial composting | horti-footprint

Biowaste $\{N L\} \mid$ treatment of biowaste (as DRY

$0.0316 \mathrm{~kg}$

(1)

$\begin{array}{llllll}(5) & 2 & 3 & 2 & 2 & 2.25 \\ (1) & 2 & 3 & 2 & 2 & 2.25\end{array}$

MASS), industrial composting | horti-footprint

Municipal solid waste $\{\mathrm{NL}\} \mid$ treatment of,

$0.00387 \mathrm{~kg}$

(1)

(1)

1

1

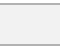

incineration | Cut-off, S

Table footnotes:

1. Benefits of Nature dataset from Roses cultivation; Unless other footnote is given, links between use and process defined by Benefits of Nature

2. Process is modelled for HortiFootprint project; explained in section 4.1 .2

3. Each bunch is wrapped in a transparent film4Lumini

4. The process has been accounted for on the basis of the ASABE 497 (ASABE 2011) standard for fuel consumption. The type of machinery was chosen consulting machinery manufacturers and experts.

5. This process includes calculations for the reactive $\mathrm{N}$ species in agreement with IPCC Tier 2 methodologies (Vonk et al., 2018)

6. Calculated to account for residues from cultivation losses and pruning.

Table 4.2 Inputs, outputs, elementary flows of the rose plant protection

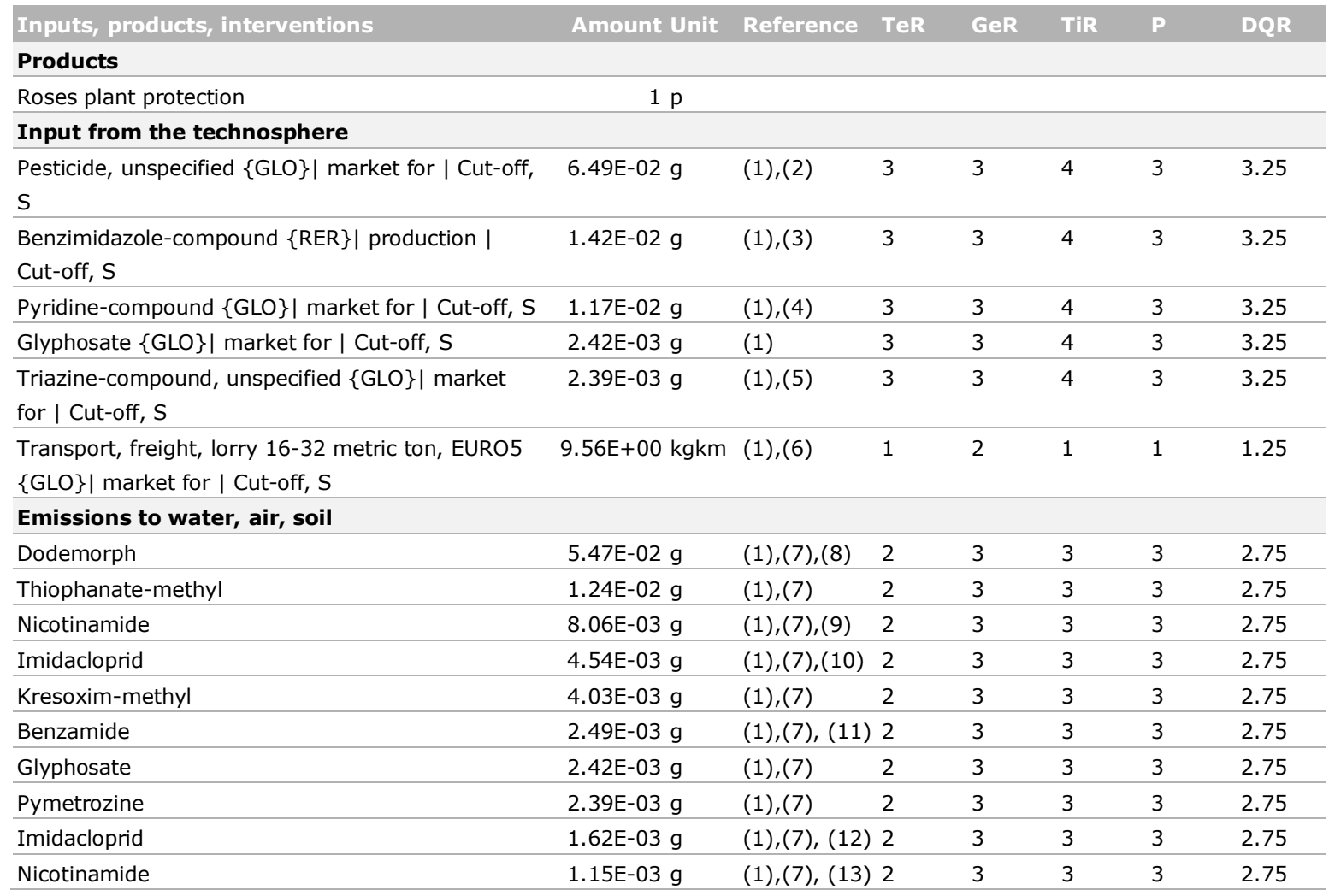

Table footnotes:

1. Benefits of Nature dataset from Rose cultivation; Selected active ingredients in pesticide formulations with a $0.5 \%$ impact cut-off (relative to largest use)

2. Used as a proxy for the production of dodemorph, imidacloprid, kresoxim methyl and acetamiprid

3. Used as a proxy for the production of thiophanate methyl

4. Used as a proxy for the production of boscalid, fluopyram, flonicaminde

5. Used as a proxy for the production of pymetrozine

6. Assuming each $\mathrm{g}$ is transported in a $1 \% \mathrm{~m} / \mathrm{m}$ concentration is transported $1000 \mathrm{~km}$; including $1 / 1000 \mathrm{~kg}$ conversion

7. Distributed according to PEF Guide: $9 \%$ to air, $1 \%$ to water, $90 \%$ to soil; no consideration of greenhouse.

8. Proxy for Dodemorph acetate

9. Proxy for Boscalid

10. Proxy for Thiamethoxam

11. Proxy for Fluopyram

12. Proxy for Acetamiprid

13. Proxy for Flonicamide 
Table 4.3 Inputs, outputs, elementary flows and land use of the rose packaging (secondary and tertiary)

\begin{tabular}{|c|c|c|c|c|c|c|c|}
\hline Inputs, products, interventions & Amount & Reference & TeR & GeR & TiR & $\mathbf{P}$ & DQR \\
\hline \multicolumn{8}{|l|}{ Product } \\
\hline Packaging of one rose stem at commercial grade & $1 \mathrm{p}$ & & & & & & \\
\hline Roses cart production and use & 5.29E-06 p & $(1)$ & 1 & 2 & 1 & 2 & 1.5 \\
\hline $\begin{array}{l}\text { Single use of } 577 \text { bucket, including production } \\
\& \text { cleaning }\end{array}$ & $0.0143 p$ & $(2)$ & 1 & 1 & 1 & 2 & 1.25 \\
\hline
\end{tabular}

Table footnotes:

1. The rose cart use is based on information from Van der Meij (2018, personal communication), in particular each cart is composed of 3 layers.

Each layer contains 9 buckets which are filled with water to preserve the rose. Each bucket contains 7 bunches of 10 flowers each.

2. This process is based on a Benefits of Nature default generic dataset.

Table 4.4 Inputs, outputs, elementary flows and land use of the rose cart production and use

\begin{tabular}{|c|c|c|c|c|c|c|c|}
\hline Inputs, products, interventions & Amount Unit & Reference & TeR & GeR & THR & $\mathbf{P}$ & DQR \\
\hline \multicolumn{8}{|l|}{ Product } \\
\hline Roses cart production and use & $1 \mathrm{p}$ & & & & & & \\
\hline $\begin{array}{l}\text { Aluminium, primary, ingot }\{\text { IAI Area, EU27 \& } \\
\text { EFTA }\} \mid \text { market for | Cut-off, S }\end{array}$ & $32.7 \mathrm{~kg}$ & $(1)$ & 2 & 2 & 1 & 2 & 1.75 \\
\hline Steel, low-alloyed $\{G L O\} \mid$ market for | Cut-off, S & $1.72 \mathrm{~kg}$ & $(1)$ & 2 & 2 & 1 & 2 & 1.75 \\
\hline $\begin{array}{l}\text { Transport, freight, lorry }>32 \text { metric ton, EURO6 } \\
\{\text { GLO\}| market for | Cut-off, } U\end{array}$ & 34400 kgkm & $(1)$ & 2 & 2 & 1 & 2 & 1.75 \\
\hline $\begin{array}{l}\text { Transport, sea ship, } 120000 \text { DWT, 80\%LF, long, } \\
\text { default/GLO Economic }\end{array}$ & $34400 \mathrm{kgkm}$ & $(1)$ & 2 & 2 & 1 & 2 & 1.75 \\
\hline
\end{tabular}

Table footnotes:

1. Benefits of Nature dataset from Roses cultivation; The rose cart use is based on information from Van der Meij (2018, personal communication), in particular each cart is made of aluminium

Table 4.5 Inputs, outputs, elementary flows and land use of the single use of the 577 bucket, including production \& cleaning

\begin{tabular}{|c|c|c|c|c|c|c|c|}
\hline Inputs, products, interventions & Amount Unit & Reference & TeR & GeR & TiR & $\mathbf{P}$ & DQR \\
\hline \multicolumn{8}{|l|}{ Products } \\
\hline $\begin{array}{l}\text { Single use of } 577 \text { bucket, including production \& } \\
\text { cleaning }\end{array}$ & $1 \mathrm{p}$ & & & & & & \\
\hline \multicolumn{8}{|l|}{ Input from the technosphere } \\
\hline $\begin{array}{l}\text { Polypropylene, granulate }\{\text { GLO }\} \text { | market for | Cut- } \\
\text { off, } \mathrm{S}\end{array}$ & $0.574 \mathrm{~g}$ & $(1)$ & 3 & 2 & 2 & 2 & 2.25 \\
\hline Injection moulding $\{\mathrm{GLO}\} \mid$ market for | Cut-off, S & $0.574 \mathrm{~g}$ & $(1)$ & 3 & 2 & 2 & 2 & 2.25 \\
\hline $\begin{array}{l}\text { Transport, freight, lorry } 16-32 \text { metric ton, EURO5 } \\
\{\text { GLO\}| market for | Cut-off, S }\end{array}$ & $0.227 \mathrm{kgkm}$ & $(1)$ & 2 & 2 & 2 & 2 & 2 \\
\hline Tap water $\{$ GLO $\} \mid$ market group for | Cut-off, $\mathrm{S}$ & $0.03 \mathrm{~kg}$ & $(1)$ & 2 & 3 & 2 & 2 & 2.25 \\
\hline
\end{tabular}

Table footnotes:

1. Benefits of Nature default generic dataset 
Table 4.6 Inputs, outputs, elementary flows and land use for storage of a single rose stem

\begin{tabular}{|c|c|c|c|c|c|c|c|c|}
\hline Inputs, products, interventions & Amount & Unit & Reference & TeR & GeR & TiR & $\mathbf{P}$ & DQR \\
\hline \multicolumn{9}{|l|}{ Products } \\
\hline R4C short storage energy & 1 & $\mathrm{p}$ & & & & & & \\
\hline $\begin{array}{l}\text { Electricity, low voltage }\{\mathrm{NL}\} \mid \text { market for | Cut-off, } \\
\mathrm{S}\end{array}$ & 0.0335 & kWh & $(1)$ & 1 & 2 & 2 & 2 & 1.75 \\
\hline
\end{tabular}

Table footnotes:

1. Based on project expert group. Considering 1 single day of refrigerated storage.

Table 4.7 Inputs, outputs, elementary flows and land use for international transport of a single rose stem

\begin{tabular}{|c|c|c|c|c|c|c|c|c|}
\hline Inputs, products, interventions & Amount & Unit & Reference & TeR & GeR & THR & $\mathbf{P}$ & DQR \\
\hline \multicolumn{9}{|l|}{ Products } \\
\hline International transport & & $\mathrm{p}$ & & & & & & \\
\hline $\begin{array}{l}\text { Transport, freight, lorry with refrigeration } \\
\text { machine, cooling }\{G L O\} \mid \text { market for | Cut-off, S }\end{array}$ & 72.9 & $\mathrm{kgkm}$ & (1) & 2 & 2 & 1 & 2 & 1.5 \\
\hline $\begin{array}{l}\text { Transport, freight, sea, transoceanic ship with } \\
\text { reefer, cooling }\{G L O\} \mid \text { market for | Cut-off, S }\end{array}$ & 3.4 & $\mathrm{kgkm}$ & (1) & 2 & 2 & 1 & 2 & 1.5 \\
\hline
\end{tabular}

Table footnotes:

1. Based on statistics from Royal FloraHolland (2018).

Table 4.8 Inputs, outputs, elementary flows and land use for retail of $170 \mathrm{~cm}$ rose stem

\begin{tabular}{|c|c|c|c|c|c|c|c|c|}
\hline Inputs, products, interventions & Amount & Unit & Reference & TeR & GeR & TiR & $\mathbf{P}$ & DQR \\
\hline \multicolumn{9}{|l|}{ Products } \\
\hline Roses retail & 1 & $\mathrm{p}$ & & & & & & \\
\hline \multicolumn{9}{|l|}{ Input from the technosphere } \\
\hline $\begin{array}{l}\text { Electricity, low voltage }\{N L\} \mid \text { market for | Cut-off, } \\
S \text { (horti-footprint retail) }\end{array}$ & 0.017 & $\mathrm{kWh}$ & (1) & 2 & 2 & 2 & 2 & 2 \\
\hline $\begin{array}{l}\text { Single use of } 577 \text { fust, including production \& } \\
\text { cleaning }\end{array}$ & 0.0143 & $\mathrm{p}$ & (1) & 2 & 2 & 2 & 2 & 2 \\
\hline $\begin{array}{l}\text { Tap water }\{\text { Europe without Switzerland }\} \text { | market } \\
\text { for | Cut-off, S }\end{array}$ & 0.188 & $\mathrm{~kg}$ & (1) & 2 & 2 & 2 & 2 & 2 \\
\hline
\end{tabular}

Table footnotes:

1. Benefits of Nature dataset from Roses cultivation

Table 4.9 Inputs, outputs, elementary flows and land use for the use of $170 \mathrm{~cm}$ rose stem

\begin{tabular}{|c|c|c|c|c|c|c|c|c|}
\hline Inputs, products, interventions & Amount & Unit & Reference & TeR & GeR & TiR & $\mathbf{P}$ & DQR \\
\hline \multicolumn{9}{|l|}{ Products } \\
\hline Rose use & 1 & $\mathrm{P}$ & & & & & & \\
\hline $\begin{array}{l}\text { Flat glass, uncoated }\{\text { RER }\} \text { | production | Cut-off, } \\
\mathrm{S}\end{array}$ & 3.84 & $g$ & $(1)$ & 3 & 3 & 2 & 3 & 2.75 \\
\hline $\begin{array}{l}\text { Transport, freight, lorry } 16-32 \text { metric ton, EURO6 } \\
\{G L O\} \mid \text { market for | Cut-off, S }\end{array}$ & 0.196 & $\mathrm{kgkm}$ & (1) & 3 & 3 & 2 & 3 & 2.75 \\
\hline
\end{tabular}

Table footnotes:

1. Based on assumptions that the rose is put in a cylindrical glass vase filled with water. The glass vase is $3 \mathrm{~cm}$ thick and has a diameter of

$10 \mathrm{~cm}$ and filled for the first $7.5 \mathrm{~cm}$ with water. 
Table 4.10 Inputs, outputs, elementary flows and land use for the disposal of $1 \mathrm{stem} 70 \mathrm{~cm}$ rose

\begin{tabular}{|c|c|c|c|c|c|c|c|}
\hline Inputs, products, interventions & Amount Unit & Reference & TeR & GeR & TiR & $\mathbf{P}$ & DQR \\
\hline \multicolumn{8}{|l|}{ Products } \\
\hline Rose disposal & $1 \mathrm{p}$ & & & & & & \\
\hline $\begin{array}{l}\text { Transport, freight, lorry } 16-32 \text { metric ton, EURO6 } \\
\{\text { GLO\}| market for | Cut-off, S }\end{array}$ & $5.1 \mathrm{kgkm}$ & (1) & 2 & 2 & 1 & 2 & 1.75 \\
\hline $\begin{array}{l}\text { Biowaste }\{\text { RoW }\} \text { | treatment of biowaste by } \\
\text { anaerobic digestion | Cut-off, } \mathrm{S}\end{array}$ & $0.1 \mathrm{~kg}$ & (1) & 2 & 2 & 1 & 2 & 1.75 \\
\hline
\end{tabular}

Table footnotes:

1. Based on project expert group

\subsubsection{Generic Processes for PEFCR Horticulture}

The processes related to operating the Cogeneration of Heat and Power ( $\mathrm{CHP}$ ) and $\mathrm{CO}_{2}$ from OCAP or flue gas treatment were developed for the purpose of the RP-study (Table 4.11 and 4.12).

Table 4.11 Inputs, outputs, elementary flows and land use of the CHP production

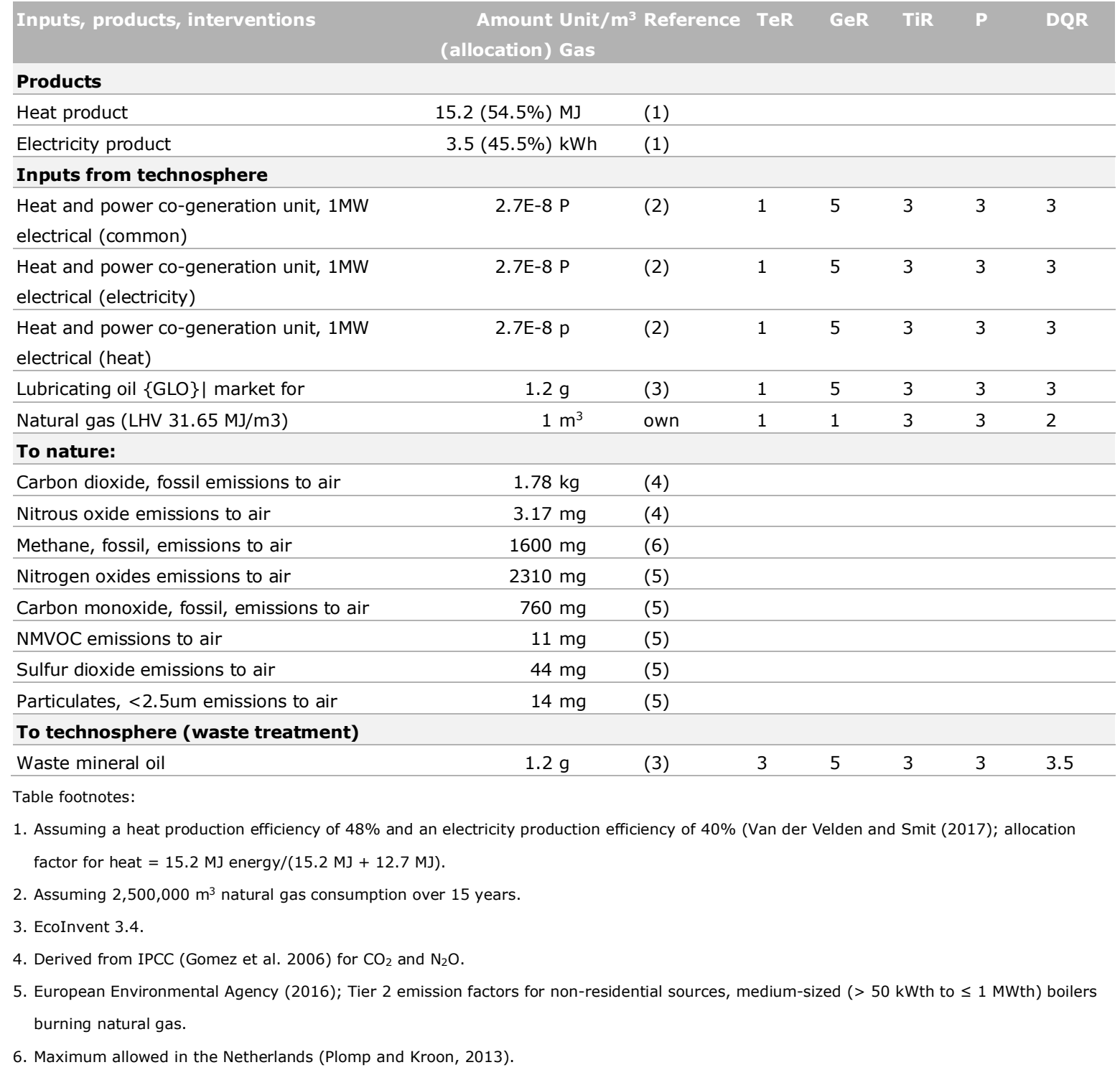


Table 4.12 Inputs, outputs, elementary flows and land use of the flue gas treatment purified carbon dioxide production (or from external source)

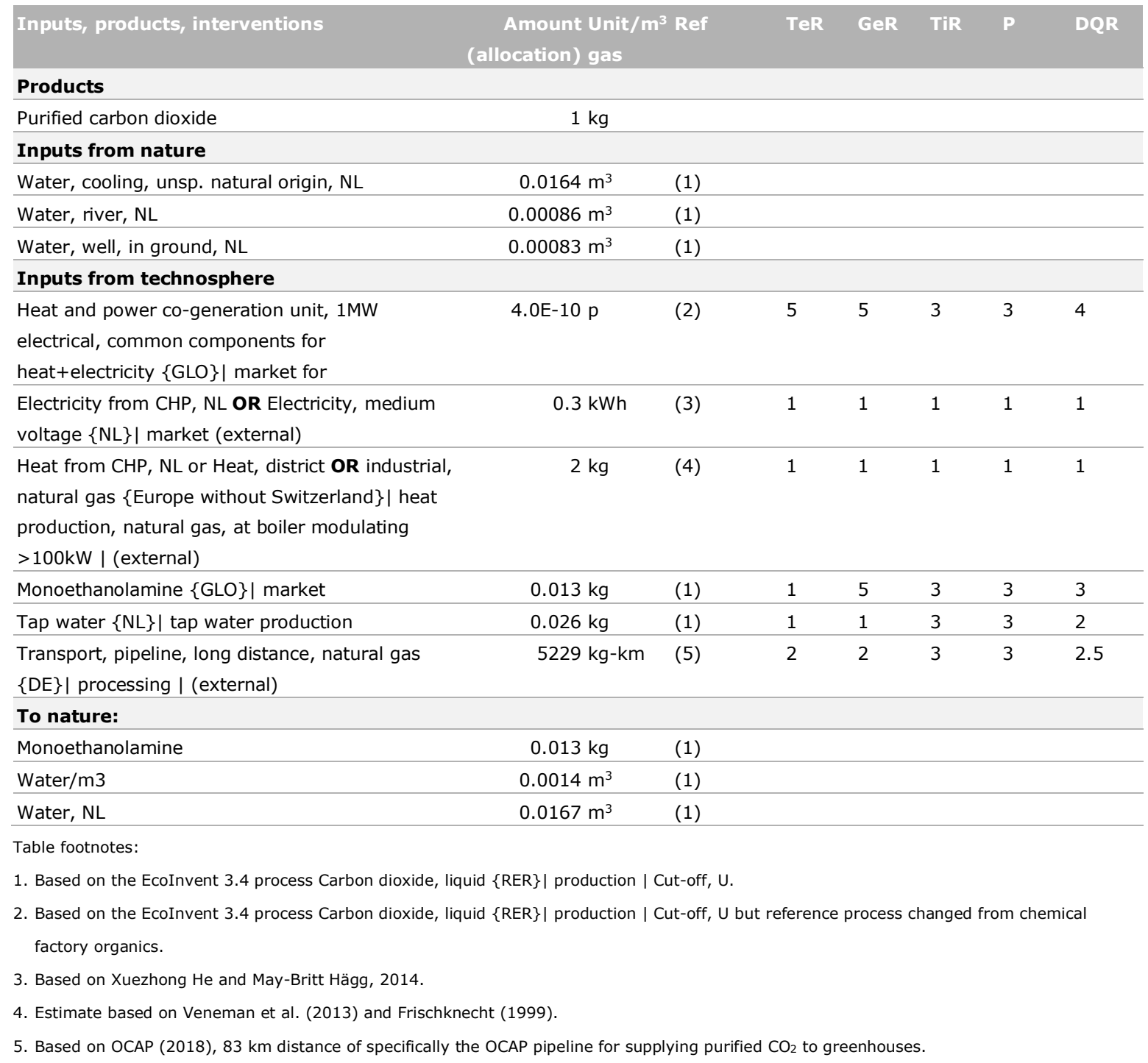

\subsection{Data collection procedures}

The organisation Benefits of Nature had collected typical data from three companies for prior advisory work for these companies, using a standardised Excel sheet. In this sheet, the amount of used materials (e.g. cuttings, substrate, pots, fertilisers, crop protection), energy and water usage, production figures, CHP-data and product compositions are filled in. Additional information not used for original advice (e.g. capital goods) were gathered separately from existing literature, LCI databases and own assumptions. The sources and the treatment of data gaps are described in the following sections.

\subsection{Methodological assumptions used in the representative product study}

\subsubsection{Linking usage data to background (EcoInvent processes) datasets}

For materials, a relevant global average, 'market for'-reference is preferably used. As the supply chains are mostly comprised of multiple links, the origin of the material is mostly unknown. If a direct 
match between database and material is not found, a proxy is used. This is for instance the case for many chemicals, where the specific substance is not available in the database and a reference for the compound type is used instead. Crop protection chemicals were linked twice independently with their proxies by two of the authors, yielding highly different results. This had no substantial effect on the final results. For energy, the most relevant local, regional or country-specific reference is used.

A longlist of usage data and links to background data was available from Benefits of Nature, consisting of 137 items. Data items for which the impact per mass unit needs to be 100 times larger in order to have an impact similar to the largest impacts were not included (this can be seen as a 'worst case impact cut-off approach'). This approach limited the data entry burden and excluded data that does not affect the data quality requirements.

\subsubsection{Direct emissions of $\mathrm{C}, \mathrm{N}$ and $\mathrm{P}$ from fertilisers}

A PEFCR Guidance (Zampori and Pant, 2019) compliant approach was followed:

- Usage of all fertilisers was collected in g per reference flow for the cultivation stage

- The usages are converted to use of elementary $\mathrm{N}$ and $\mathrm{P}$ and summed and amounts included in harvested product were subtracted from these total loads.

- $\mathrm{NH}_{3}$ emission to air, $\mathrm{NO}_{3}$ emission to water, $\mathrm{N}_{2} \mathrm{O}$ emission to air and Phosphate to water are calculated from the total loads compliant with the PEF guide: the $\mathrm{NO}_{3}$ emission is the balance of $\mathrm{N}$ application and losses to $\mathrm{NH}_{3}, \mathrm{~N}_{2} \mathrm{O}, \mathrm{N}_{2}$.

- In addition, $\mathrm{CO}_{2}$ emissions from urea application are calculated and included as fossil emissions.

This approach is quite inaccurate and conservative because water emissions are usually collected as excess irrigation water and fed back into the fertigation system. A certain share of the water is purified and emitted to the surface water once the salinity of the recirculated water becomes too high.

\subsubsection{Including Plant Protection Products in LCA}

A preliminary approach was followed to test if active ingredients in the crop protection product contribute to toxicity impacts:

- Total usages for the cultivation stage were taken from separate data file from Benefits of Nature's company datasets. Each use is reported in the list for all components of the product, not only active substance, so that all components are known for each formulation. This results in 70 items.

- Only the active ingredient of each formulation was considered for inclusion as input and emissions.

- These were included if their mass use was at least $1 \%$ of the largest active ingredient use (this is the same principle as the 'worst case impact cut-off approach'). Ten active ingredients were included. Two ingredients that were above the cut-off could not be included since no reliable proxy was available, because they were more or less natural products with a heterogenic chemical composition.

- The emissions of active ingredients and most used substances were entered as a distribution over air, water, soil according to the PEFCR guidance recommendation of $1 \%$ to air, $9 \%$ to water, $90 \%$ to soil. Either the substance itself or a proxy based on molecular structure was included, provided that it could be characterised with the USETOX characterisation factor set of the EF characterisation method. 


\section{$5 \quad$ PEF impact assessment results}

\subsection{Most relevant life cycle impact categories}

The most relevant life cycle impact categories for Roses are: Climate change; Resource use, energy carriers; Resource use, materials and metals, Acidification terrestrial and freshwater (Figure 5.1). These contribute cumulatively to $80 \%$ the total environmental impact. These impact categories will be reported in detail. Although ecotoxicity freshwater is not included in the weighted results, this category is selected as relevant due to the perceived importance of the environmental impact of pesticides.

Contribution of the impact categories to the total environmental impact

\begin{tabular}{|c|c|}
\hline Climate change & $44 \%$ \\
\hline Resource use, energy carriers & $36 \%$ \\
\hline Acidification terrestrial and freshwater & $4 \%$ \\
\hline Photochemical ozone formation, $\mathrm{HH}$ & $4 \%$ \\
\hline Eutrophication terrestrial & $3 \%$ \\
\hline Respiratory inorganics & $3 \%$ \\
\hline Eutrophication freshwater & $2 \%$ \\
\hline Resource use, mineral and metals & $2 \%$ \\
\hline Eutrophication marine & $2 \%$ \\
\hline Water scarcity & $1 \%$ \\
\hline Ozone depletion & $1 \%$ \\
\hline Ionising radiation, $\mathrm{HH}$ & $0 \%$ \\
\hline Land use & $0 \%$ \\
\hline
\end{tabular}

Figure 5.1 Contribution of the life cycle impact categories to the normalised and weighted impact of roses 


\subsection{Most relevant life cycle stages}

Contribution of the life cycle stages to the most relevant impact categories

\begin{tabular}{|c|c|c|c|c|}
\hline $80 \%$ & & & & \\
\hline $60 \%$ & & & & \\
\hline $40 \%$ & & & & \\
\hline $20 \%$ & & & & \\
\hline $0 \%$ & Climate change & $\begin{array}{l}\text { Resource use, } \\
\text { energy carriers }\end{array}$ & $\begin{array}{l}\text { Acidification } \\
\text { terrestrial and } \\
\text { freshwater }\end{array}$ & $\begin{array}{l}\text { Ecotoxicity } \\
\text { freshwater }\end{array}$ \\
\hline End-of-life & $1 \%$ & $0 \%$ & $1 \%$ & $0 \%$ \\
\hline Use & $1 \%$ & $0 \%$ & $2 \%$ & $6 \%$ \\
\hline - Retail & $1 \%$ & $1 \%$ & $1 \%$ & $0 \%$ \\
\hline$\square$ Storage & $2.0 \%$ & $2 \%$ & $2 \%$ & $1 \%$ \\
\hline \begin{tabular}{|l|} 
Distribution \\
\end{tabular} & $6 \%$ & $5 \%$ & $13 \%$ & $9 \%$ \\
\hline — Packaging & $0.8 \%$ & $1 \%$ & $2 \%$ & $1 \%$ \\
\hline$\square$ Cultivation - Other processes & $11 \%$ & $4 \%$ & $26 \%$ & $76 \%$ \\
\hline - Cultivation - Heating & $50 \%$ & $57 \%$ & $32 \%$ & $2 \%$ \\
\hline 口 Cultivation - Electricity & $26 \%$ & $30 \%$ & $17 \%$ & $1 \%$ \\
\hline 口 Cultivation - Capital Goods & $1 \%$ & $1 \%$ & $4 \%$ & $3 \%$ \\
\hline
\end{tabular}

Figure 5.2 Contribution of the life cycle stages of rose stem to the relevant impact categories

Figure 5.2 shows the contribution of the rose stem life cycle stages to the relevant impact categories. Contributions from individual processes are shown in Table 5.1. We observe that the most relevant (contributing cumulatively to $80 \%$ of one of the most relevant environmental impact categories) life cycle stage of roses is cultivation (which includes the sub-stages energy, capital goods, and carbon dioxide production and cultivation) to all relevant impact categories. Besides cultivation, transport/distribution is also a relevant stage, together with crop protection specifically for ecotoxicity.

Table 5.1 Contribution of the most relevant processes and life cycle stages to the most relevant impact categories of roses

\begin{tabular}{|c|c|c|c|c|c|}
\hline & $\begin{array}{l}\text { Climate } \\
\text { change }\end{array}$ & $\begin{array}{r}\text { Resource - } \\
\text { energy }\end{array}$ & Acidification & Ecotoxicity & $\begin{array}{l}\text { Life Cycle } \\
\text { Stage }\end{array}$ \\
\hline Heat from $\mathrm{CHP}$ & $42 \%$ & - & $19 \%$ & - & Cultivation \\
\hline Natural gas production & $12 \%$ & $86 \%$ & $19 \%$ & - & Cultivation \\
\hline Emissions during cultivation & $4 \%$ & - & $9 \%$ & - & Cultivation \\
\hline Road transport & - & - & $7 \%$ & $8 \%$ & Distribution \\
\hline Air transport & - & - & $6 \%$ & - & Distribution \\
\hline Glass greenhouse & - & - & $3 \%$ & - & Cultivation \\
\hline Roses pesticide use & - & - & - & $69 \%$ & Cultivation \\
\hline
\end{tabular}




\subsection{Impact indicator results of roses}

Table 5.2 shows the impact indicator results of roses.

Table 5.2 Impact indicator results

\begin{tabular}{|c|c|c|}
\hline Midpoint indicator & Unit & Total \\
\hline Climate change & $\mathrm{kg} \mathrm{CO} 2$ eq & $1.08 \mathrm{E}+00$ \\
\hline Ozone depletion & kg CFC11 eq & $1.36 \mathrm{E}-07$ \\
\hline Photochemical ozone formation, $\mathrm{HH}$ & $\mathrm{kg}$ NMVOC eq & $2.23 \mathrm{E}-03$ \\
\hline Respiratory inorganics & disease inc. & $1.27 \mathrm{E}-08$ \\
\hline Cancer human health effects & CTUh & $3.69 E-09$ \\
\hline Acidification terrestrial and freshwater & $\mathrm{mol} \mathrm{H}+\mathrm{eq}$ & $2.36 \mathrm{E}-03$ \\
\hline Eutrophication freshwater & $\mathrm{kg} \mathrm{P} \mathrm{eq}$ & $1.19 E-04$ \\
\hline Eutrophication marine & $\mathrm{kg} \mathrm{N} \mathrm{eq}$ & $9.76 \mathrm{E}-04$ \\
\hline Water scarcity & $\mathrm{m}^{3}$ depriv. & $6.01 \mathrm{E}-02$ \\
\hline Resource use, energy carriers & MJ & $1.86 \mathrm{E}+01$ \\
\hline Resource use, mineral and metals & $\mathrm{kg} \mathrm{Sb} \mathrm{eq}$ & $9.71 \mathrm{E}-07$ \\
\hline Climate change - fossil & $\mathrm{kg} \mathrm{CO} 2 \mathrm{eq}$ & $1.07 \mathrm{E}+00$ \\
\hline Climate change - biogenic & $\mathrm{kg} \mathrm{CO} 2$ eq & $0.00 \mathrm{E}+00$ \\
\hline Climate change - land use and transform. & $\mathrm{kg} \mathrm{CO} 2 \mathrm{eq}$ & $1.38 \mathrm{E}-04$ \\
\hline
\end{tabular}

\subsection{Most relevant processes and elementary flows of roses}

In the following sections, the detailed results are shown for the contributions of individual life cycle stages and substage to the most relevant impact categories, as shown in 5.1.

\subsubsection{Climate change}

Figure 5.3 show the relevant processes that contribute to at least $80 \%$ of the climate change impact of 1 stem of $70 \mathrm{~cm}$ rose. In particular, the large contribution of heating and electricity during the cultivation stage to climate change is observed. 


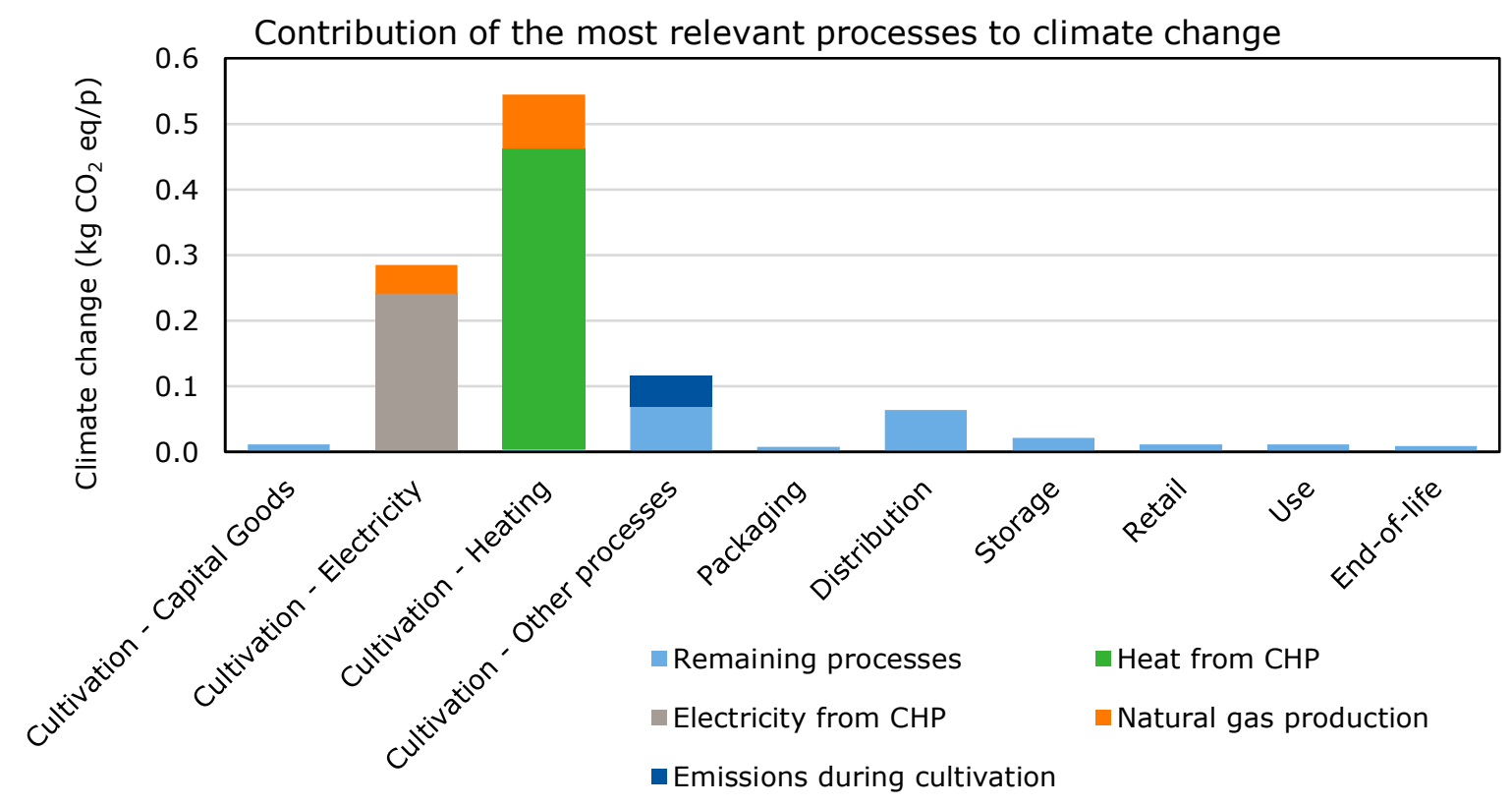

Figure 5.3 Contribution of the most relevant processes to at least $80 \%$ of the climate change impact of 1 stem $70 \mathrm{~cm}$ rose

\subsubsection{Resource use, energy carriers}

Figure 5.4 shows the relevant processes that contribute to at least $80 \%$ of the resource use, energy carriers impact per FU (1 stem $70 \mathrm{~cm}$ rose). In particular, the large contribution of heating and electricity during the cultivation stage to resource use, energy carriers.

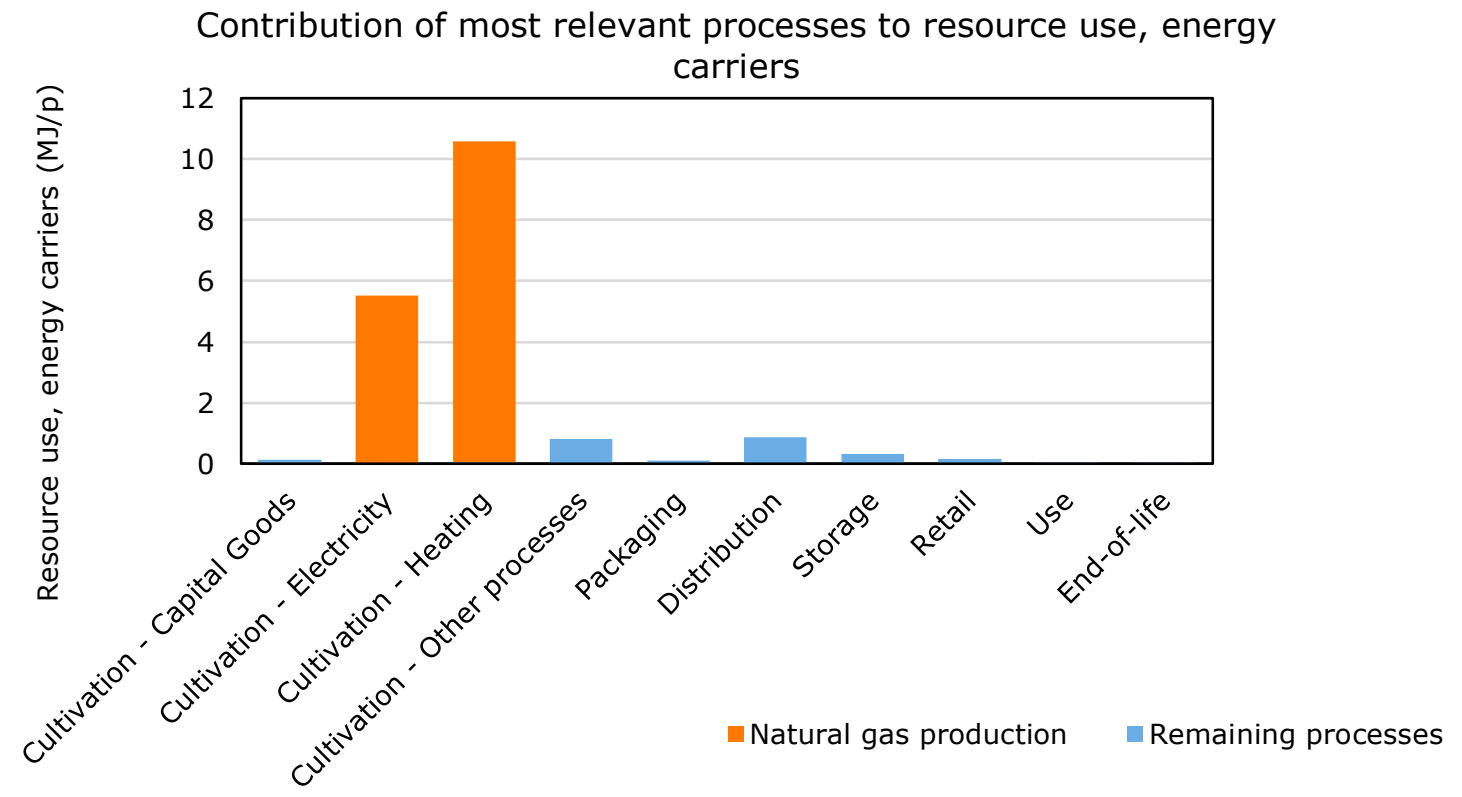

Figure 5.4 Resource use, energy carriers impact in MJ per 1 stem of $70 \mathrm{~cm}$ of roses per life cycle stage and relevant process 


\subsubsection{Acidification terrestrial and freshwater}

Figure 5.5 show the relevant processes that contribute to at least $80 \%$ of the acidification terrestrial and freshwater impact per FU ( 1 stem $70 \mathrm{~cm}$ rose). The most relevant processes with respect to acidification terrestrial and fresh water are: heating, other processes, electricity and distribution.

Contribution of most relevant processes to acidification terrestrial and

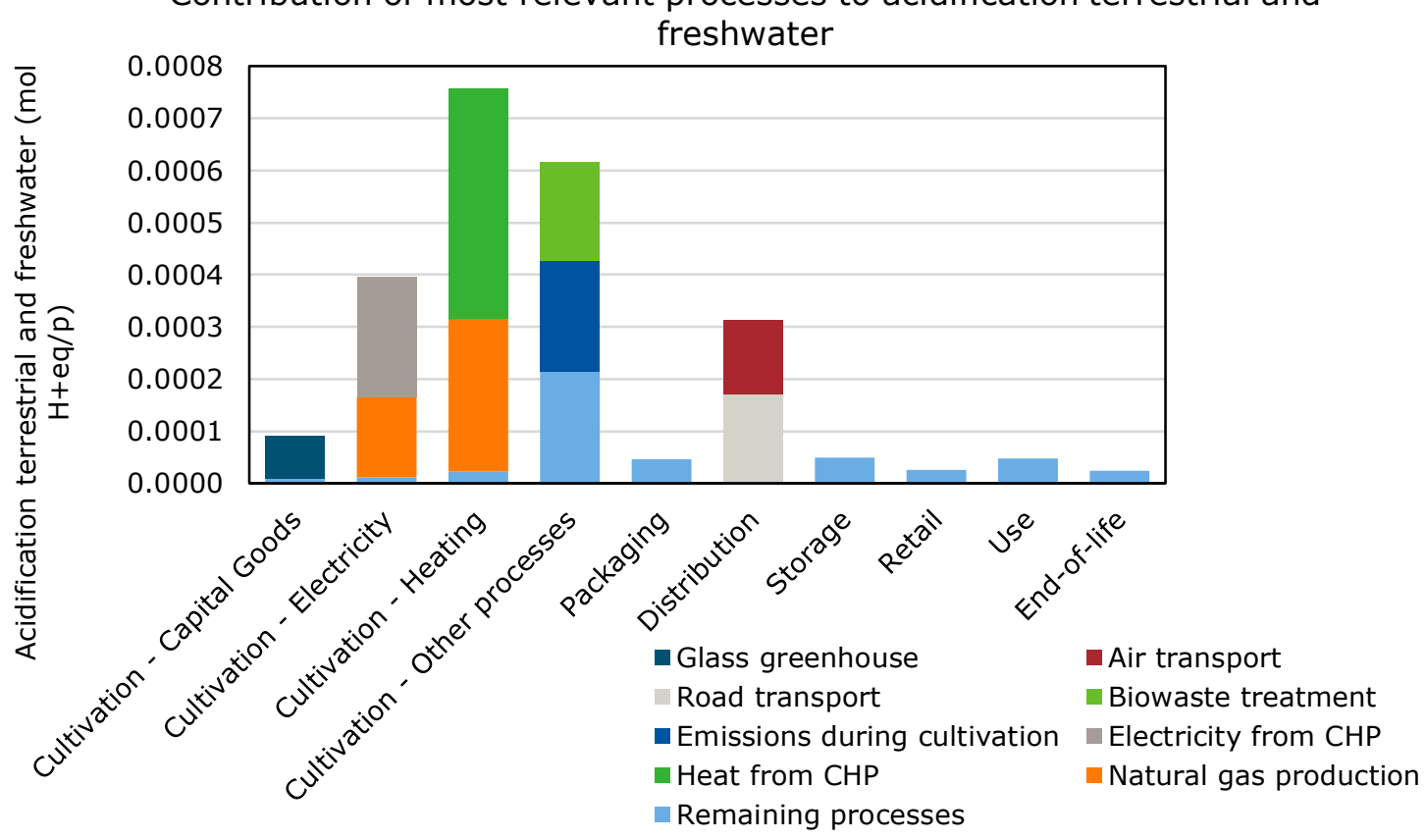

Figure 5.5 Acidification terrestrial and freshwater impact in mol $\mathrm{H}+$ eq per FU (per $1 \mathrm{stem} 70 \mathrm{~cm}$ rose) per life cycle stage and relevant process

\subsubsection{Ecotoxicity freshwater}

Figure 5.6 show the relevant processes that contribute to at least $80 \%$ of the ecotoxicity freshwater impact of $1 \mathrm{FU}$ functional unit ( 1 stem $70 \mathrm{~cm}$ rose). The pesticide use within the roses cultivation contributes most. However, a small overview of the individual emissions (Table 5.3) indicates the complexities. The nicotinamide emissions to soil and air contribute most. These represent a proxy for two crop protection products, namely Boscalid and Flonicamide. The most used product Dodemorph acetate (used approximately 6 times more than Boscalid) also shows up but with a small contribution. Heavy metal emissions from transport during distribution also contribute to the $80 \%$, while several crop protection products do not show up.

The use of a proxy is a highly uncertain illustration of what might happen during cultivation. The overall estimation of ecotoxicity impacts is highly uncertain, mainly because of the process of choosing proxies. Nicotinamide is not actually applied as a pesticide. It would be more reliable but very laborious to estimate USEtox Characterization Factors. Benefits of Nature does calculate characterisation factors, albeit based on the USES-LCA model. Their calculations indicate that Flonicamide and Boscalid are 200 times less impactful than their proxy nicotinamide. Excluding their impact reduces the overall freshwater toxicity by $63 \%(!)$, and metal emissions from transportation become even more relevant. 


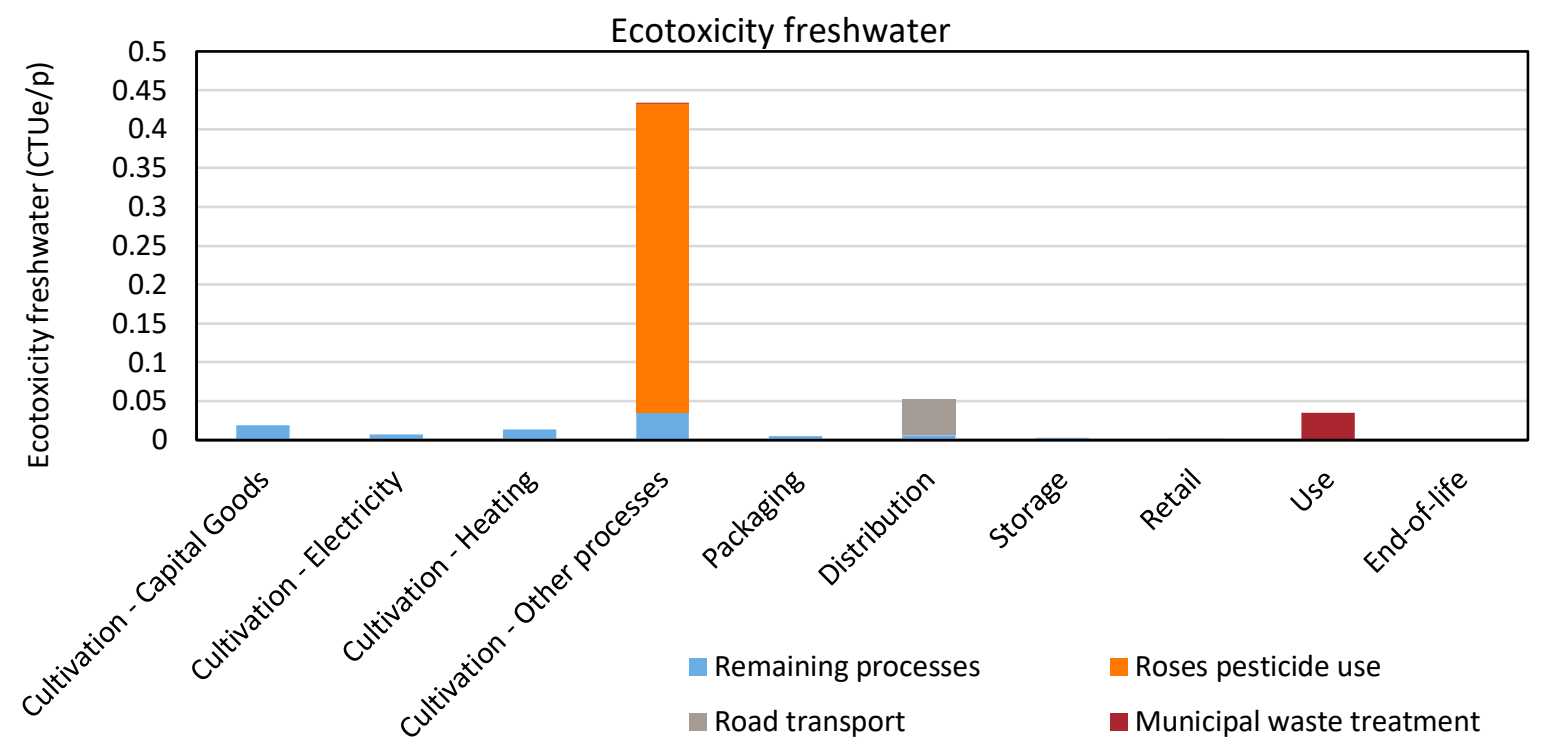

Figure 5.6 Freshwater ecotoxicity impact in CTUe per FU $\mathrm{FU}^{-1}$ (1 stem $70 \mathrm{~cm}$ rose) per life cycle stage and relevant process

Table 5.3 Contributions of different emissions to Freshwater Ecotoxicity impacts\%

\begin{tabular}{lr} 
Emission & $59 \%$ \\
\hline Nicotinamide - Soil & $4 \%$ \\
\hline Nicotinamide - Air & $7 \%$ \\
\hline Antimony - Air & $2 \%$ \\
\hline Nicotinamide - Water & $1 \%$ \\
\hline Dodemorph - Water & $3 \%$ \\
\hline Zinc - Water & $1 \%$ \\
\hline Kresoxim-methyl - Water & $1 \%$ \\
\hline Dodemorph - Soil & $22 \%$ \\
\hline Remaining substances - & \\
\hline
\end{tabular}




\section{Interpretation}

\subsection{Climate change and resource use, energy}

The results for the categories 'climate change' and 'resource use, energy' have a relatively high certainty, because most impact takes place during the processes owned by the rose grower for which primary data is used and there is also good confidence in the greenhouse gas emission data of the background databases. However, this assessment does not take into account soil/substrate $\mathrm{C}$ dynamics, deemed to be relevant. There are also several assumptions that affect the results, such as the electricity and heat production efficiencies in the CHP system and the input data for producing purified carbon dioxide. The resource use, energy carriers indicator results also have a relatively high certainty as it is largely linked to primary data on energy use, with the same sensitivity to the mentioned assumptions.

The other indicators however are very sensitive to the background data and the reliability of the elementary flow data for those indicators in the background databases is much weaker.

\subsection{Acidification, terrestrial and freshwater}

The impact in this category is more sensitive to the background data and the reliability of the elementary flow data, especially for natural gas production. This impact is also sensitive to the assumptions on acidifying emissions during cultivation and during the heat production itself. However no detailed modelling of reactive $\mathrm{N}$ species has been carried out considering the spatial issues in relation to ammonia emissions (Corstanje et al. 2008), which have a large effect on acidification.

\subsection{Ecotoxicity, freshwater}

The results in this category are highly sensitive to the choice which substance proxy represents which active ingredient, since the USEtox characterisation factors for these proxies were used. Calculation of additional USEtox characterisation factors would be required. The simple PEFCR approach to distribution of the active ingredients over the different environmental compartments also influences the results and contributes to uncertainty. The results are also sensitive to metal emissions data of the background database. The large uncertainties in pesticide modelling (both in primary and secondary data) significantly contribute to overall uncertainty in the freshwater ecotoxicity indicator.

\subsection{Other environmental impacts}

Very few active ingredients were available in the EcoInvent database for modelling the impacts of the production of these ingredients. the latter are often not updated (due to confidentiality) or not present for the active ingredients. However, the impact of production is most likely very limited. Furthermore, the resource use, minerals and metals indicator results are highly sensitive to the material use for the capital goods for cultivation, the assumption on the technical lifetime of the greenhouse structure. 


\section{Conclusion}

This RP study is part of the development of a PEFCR for horticultural products. It is not intended to make statements about the impact of roses grown in Dutch heated greenhouses. The aim is to identify the hotspots (most relevant impact categories, life cycle stages, processes and elementary flows) and the data quality requirements for future PEFCR compliant studies.

\subsection{Most relevant impact categories and life cycle stages}

The most relevant life cycle impact categories based on weighted results are (as shown in Figure 5.1):

- Climate change

- Resource use, energy carriers

- Acidification terrestrial and freshwater.

Ecotoxicity freshwater was not included in the weighted results, but is considered relevant due to the perceived importance of the environmental impact of pesticides.

The most relevant life cycle stages of the studied roses are (as shown in Figure 5.2):

- Cultivation (which includes capital goods, electricity and heat production, carbon dioxide production, crop protection and cultivation activities) for all of the most relevant life cycle impact categories

- Distribution is also relevant for the acidification category.

\subsection{Most relevant processes}

The most relevant processes are (as shown in Table 5.1):

- Heat from CHP

- Electricity from CHP

- Natural gas production

- Emissions during cultivation

- Biowaste treatment

- Road transport

- Air transport

- Glass greenhouse

- Roses pesticide use

- Municipal waste treatment

- Remaining processes.

\subsection{Overall appreciation of the uncertainties of the results}

The uncertainty of the results is due to different factors, depending on the impact category. A large part of the uncertainty is caused by the quality of the background databases. There are also several important parameters in the foreground data which have been estimated based on various sources, which may not be fully representative for common practice. These parameters need to be critically revised if they will be used as defaults in case no accurate activity data are available. For the purpose of the current study, all assumptions and data estimations are considered adequate. 


\subsection{Sensitivity analysis}

When the allocation to heat and electricity of the grower's CHP system would be based on exergy rather than energy, the climate change and resource use, energy carriers impact indicators would be about $40-50 \%$ lower. The acidification terrestrial and freshwater indicator would be about significantly lower as well. So, this choice has a very significant effect on the results. Exergy allocation is not recommended as discussed in this report and in the draft PEFCR for horticultural products. Nevertheless, the EcoInvent database applies exergy allocation. If CHP processes from EcoInvent would be adjusted according to the current recommendation, the impact of heat from CHP from EcoInvent will increase significantly and the impact of electricity from CHP will decrease significantly, depending on how much of the heat can be utilised. It is recommended to pursue consistency between the recommendations between background databases and calculations using primary data in the long run.

\subsection{Data quality requirements}

This study aimed at identifying the data collection and data quality requirements to ensure robust and high-quality results for similar horticultural products. The requirements determined on the basis of this study are displayed in Table 7.1.

The results are compliant to the Data Needs Matrix from the PEFCR Guidance. The basic requirements are that $D Q R$ is lower or equal to 1.6 , implying good data is collected, for processes that are in the grower's control and for processes that contribute to the most relevant life cycle impact categories.

For the cultivation stage, the DQR of the overall life cycle stage cannot be determined, since the stage is modelled as multiple processes. The cultivation activities (Table 4.1), including energy and heat use, has a DQR of 1.6. It should be decided which data quality the CHP processes modelling providing heat and electricity needs to have, since it indirectly determines most environmental impacts, especially the most relevant. It should also be critically assessed which data items should be reliable within the cultivation life cycle stage and which can have a lower reliability, in order to limit data collection burden. For tracking the individual fertilisers applied and linking pesticide active ingredients to their production impacts does not show up in the results. The crop protection process (Table 4.2) has a DQR of 2.8; if freshwater toxicity (or other toxicity categories) would be selected as a relevant environmental impact, their data quality should be improved.

Table 7.1 Data quality requirements $(D Q R)$ for the different life cycle stages for roses

\begin{tabular}{lll} 
Life cycle stage & Data collection needs & Required data quality rating score) \\
Cultivation & Amounts of inputs and elementary flows & $\leq 1.6:$ Very good to excellent quality \\
\hline Post-harvest handling & No post-harvest handling & Not applicable \\
\hline Packaging & Generic data allowed & $\leq 3.0:$ Good quality \\
\hline Distribution & Amounts of main materials & $\leq 1.6:$ Very good to excellent quality \\
\hline Storage & Distance and mode & $\leq 3.0:$ Good quality \\
\hline Retail & Generic data allowed & $\leq 3.0:$ Good quality \\
\hline Use & Generic data allowed & $\leq 3.0:$ Good quality \\
\hline End of life & Percentages and types of waste treatment, & $\leq 3.0:$ Good quality \\
& generic data allowed & $\leq 3.0:$ Good quality \\
Inputs of the processes & Generic data allowed & \\
above and waste treatment & & \\
processes & &
\end{tabular}




\section{Disclaimer}

The RP study is NOT intended to make statements about the product group impacts as such, nor is it intended to be used in the context of comparison or for comparative assertions to be disclosed to the public. The results can be used to see where potential hotspots are by looking at the most relevant impact categories, life cycle stages, processes and elementary flows.

In practice, there is a large variety in greenhouse production of roses in respect to how energy is produced, and what sources of energy and purified carbon dioxide, and in what quantities, they are used. In many cases, a mix of different sources are used and the quantities will vary year by year due to weather conditions and economic developments. So, the absolute results of the current cases cannot be regarded as representative of the large variety in practice, but it is expected that the general conclusions on the hotspots and the resulting data quality requirements will apply to heated and protected production in European temperate climate zones. 


\section{Acknowledgements}

This study was carried out in the framework of the public-private partnership project HortiFootprint 'Methodology for environmental footprint TU17005' for Topsector Agri \& Food, as part of the programme 'Consumer, Market and Society'. The authors would like to thank the Product Commission Group for Roses and Piet Briët from Royal FloraHolland for insightful discussion of the results in January 2019, and Marc Ruijs from Wageningen Economic Research for his review. 


\section{References and websites}

Agri-footprint 4 (2018a). Agri-footprint 4.0. Part 1: Methodology and basic principles.

https://www.agri-footprint.com/wp-content/uploads/2018/03/Agri-Footprint-4.0-Part-1Methodology-and-basic-principles-2018.pdf

Agri-footprint 4 (2018b). Agri-footprint 4.0. Part 2: Description of data. https://www.agrifootprint.com/wp-content/uploads/2018/03/Agri-Footprint-4.0-Part-2-Description-of-data2018.pdf

ASABE (2011). ASAE D497.7 MAR 2011 Agricultural machinery management data. American Society of Agricultural and Biological Engineers, St. Joseph, Michigan

Corstanje, R., G.J.D. Kirk, M. Pawlett, R. Read, R.M. Lark (2008). Spatial variation of ammonia volatilization from soil and its scale-dependent correlation with soil properties. Eur J Soil Sci 59:1260-1270. doi: 10.1111/j.1365-2389.2008.01087.x

EC (2018). Product Environmental Footprint Category Rules Guidance - version 6.3, May 2018, European Commission, http://ec.europa.eu/environment/eussd/smgp/pdf/PEFCR_guidance_v6.3.pdf

European Environment Agency (2016). EMEP/EEA air pollutant emission inventory guidebook 2016. Technical guidance to prepare national emission inventories.

https://www.eea.europa.eu/publications/emep-eea-guidebook-2016/download

Frischknecht, R. (1999). Umweltrelevanz natürlicher Kältemittel. Ökobilanzen von Wärmepumpen und Kälteanlagen. Bundesamt für Energie (BfE), Bern as pdf-File under:

http://www.waermepumpe.ch/fe/Fr_LCA_SB_Anh.pdf

Goglio, P. (2020). Environmental footprint of tulip bulbs: Summary of the representative product study. Wageningen Economic Research, Report 2020-041g.

Gomez, D., J. Watterson, B. Americano, C. Ha, G. Maarland, E. Matsika, L. Nenge Namayanga, B. Osman-Elasha, J. Kalenga Saka, K. Treanton and R. Quadrelli (2006). Chapter 2: Stationary combustion. Volume 2, IPCC guidelines for national greenhouse gas inventories. IPCC International Panel on Climate Change, Geneva, Switzerland, p. 47

Helmes, R., T. Ponsioen, H. Blonk, M. Vieira, P. Goglio, R. van den Linden, P. Gual Rojas, D. Kan and I. Verweij-Novikova (2020a). HortiFootprint category rules: towards a PEFCR for horticultural products: Wageningen, Wageningen Economic Research. Report no 2020-041.

https://doi.org/10.18174/526452.

Helmes, R., P. Goglio and R. van der Linden (2020b). Environmental footprint of roses: Summary of the representative product study. Wageningen Economic Research, Report 2020-041f.

Helmes, R., T. Ponsioen and R. van der Linden (2020c). Environmental footprint of phalaenopsis: Summary of the representative product study. Wageningen Economic Research, Report 2020-041c.

Kan, D., L. Golsteijn and M. Vieira (2020). Environmental footprint of bananas: Summary of the representative product study. PRé Sustainability on behalf of Wageningen Economic Research, Report 2020-041e.

OCAP (2018). OCAP network. www.ocap.nl; access date November 1, 2018.

Plomp AJ, Kroon, P (2013) De mogelijke aanscherping van vijf eisen in het Besluit emissie-eisen middelgrote stookinstallaties. CEN Report. https://zoek. officielebekendmakingen.nl/blg231229.pdf

Ponsioen T., P. Goglio, R. Helmes, P. Goglio, H. Blonk, R. van der Linden and I. Verweij-Novikova (2020). Life cycle analysis of horticultural products: Memo on handling multi-functionality of combined heat and power systems. Wageningen Economic research, report 2020-041h.

Ponsioen, T. and R. Helmes (2020a). Environmental footprint of tomatoes: Summary of the representative product study. Wageningen Economic Research, Report 2020-041b.

Ponsioen, T. and R. Helmes (2020b). Environmental footprint of apples: Summary of the representative product study. Wageningen Economic Research, Report 2020-041d. 
Royal FloraHolland (2018). Jaarverslag Royal FloraHolland.

http://jaarverslag.royalfloraholland.com/\#/feiten-en-cijfers/import-export?_k=zjpdoo. Accessed 6 February 2019.

Velden, N. van der and P. Smit (2017). Effect intensivering, extensivering en energiebesparing op CO2-emissie Nederlandse glastuinbouw. Wageningen, Wageningen Economic Research, Rapport 2017-060.

Veneman, R., H. Kamphuis and D.W.F. Brilman (2013). Post-combustion CO2 capture using supported amine sorbents: a process integration study. Energy Procedia 37:2100-2108.

Wernet, G., C. Bauer, B. Steubing, J. Reinhard, E. Moreno-Ruiz and B. Weidema (2016). The EcoInvent database version 3 (Part I): overview and methodology. Int J Life Cycle Assess 21:1218-30, https://doi.org/10.1007/s11367-016-1087-8.

Xuezhong $\mathrm{H}$. and H. May-Britt (2014). Energy efficient process for CO2 capture from flue gas with novel fixed-site-carrier membranes. Energy Procedia 63:174-185

Zampori, L. and R. Pant (2019). 'Suggestions for Updating the Product Environmental Footprint (PEF) Method.' Luxembourg. https://doi.org/10.2760/424613. 
Wageningen Economic Research P.O. Box 29703

2502 LS The Hague

The Netherlands

$\mathrm{T}+31(0) 703358330$

E communications.ssg@wur.nl

www.wur.eu/economic-research

Wageningen Economic Research REPORT

2021-018
The mission of Wageningen University \& Research is "To explore the potential of nature to improve the quality of life". Under the banner Wageningen University \& Research, Wageningen University and the specialised research institutes of the Wageningen Research Foundation have joined forces in contributing to finding solutions to important questions in the domain of healthy food and living environment. With its roughly 30 branches,

6,500 employees (5,500 fte) and 12,500 students, Wageningen University \& Research is one of the leading organisations in its domain. The unique Wageningen approach lies in its integrated approach to issues and the collaboration between different disciplines.

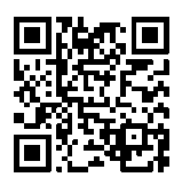





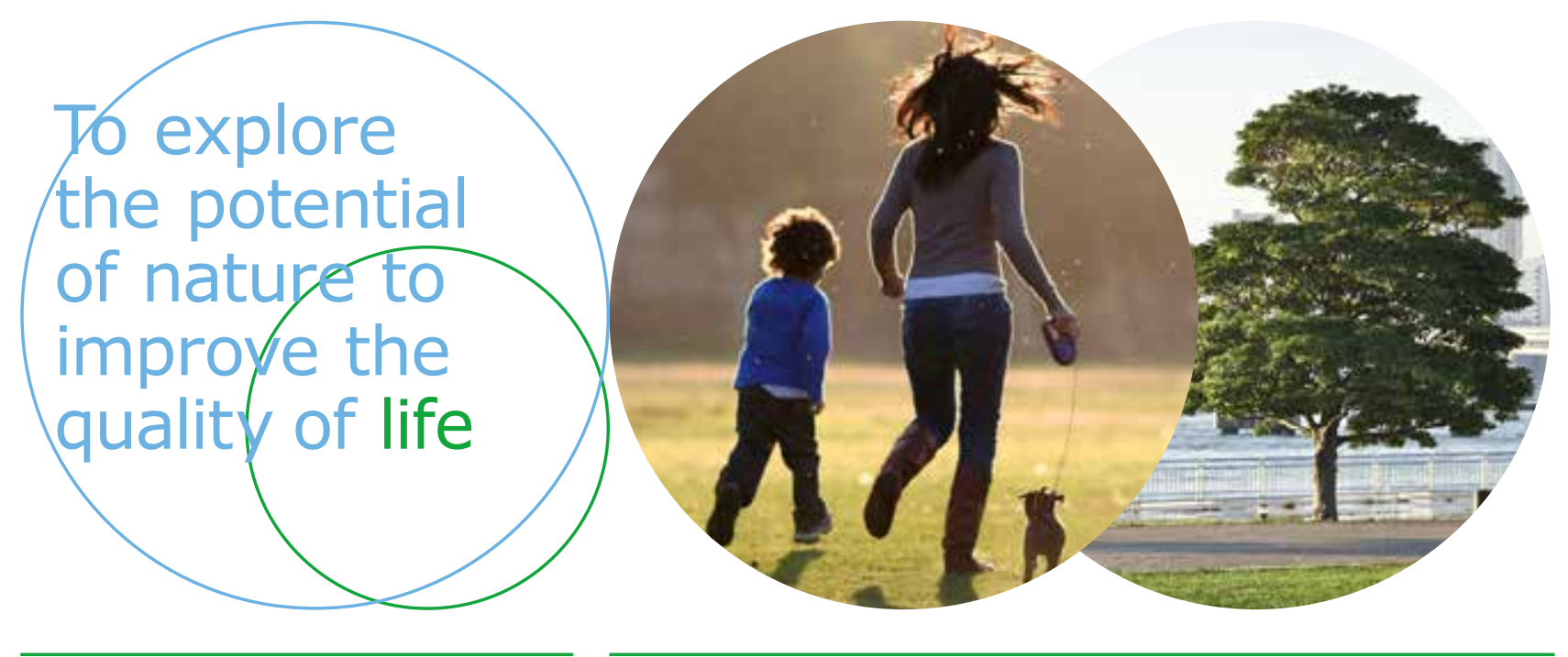

Wageningen Economic Research P.O. Box 29703

2502 LS Den Haag

The Netherlands

$\mathrm{T}+31(0) 703358330$

E communications.ssg@wur.nl

www.wur.eu/economic-research

Report 2021-018

ISBN 978-94-6395-731-1
The mission of Wageningen University \& Research is "To explore the potential of nature to improve the quality of life". Under the banner Wageningen University \& Research, Wageningen University and the specialised research institutes of the Wageningen Research Foundation have joined forces in contributing to finding solutions to important questions in the domain of healthy food and living environment. With its roughly 30 branches, 6,500 employees (5,500 fte) and 12,500 students, Wageningen University \& Research is one of the leading organisations in its domain. The unique Wageningen approach lies in its integrated approach to issues and the collaboration between different disciplines. 